
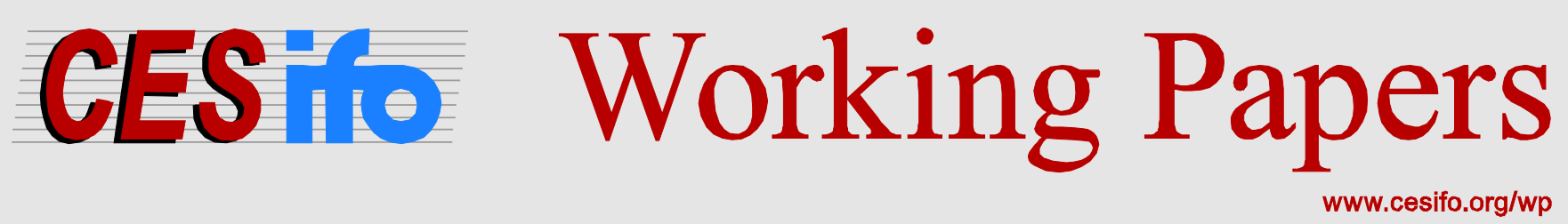

\title{
Unexpected Loan Losses and Bank Capital in an Estimated DSGE Model of the Euro Area
}

\author{
Nikolay Hristov \\ Oliver Hülsewig
}

\author{
CESIFO WORKING PAPER NO. 6160 \\ CATEGORY 7: MONETARY POLICY AND INTERNATIONAL FinANCE \\ ORIGINAL VERSION: OCTOBER 2016 \\ THIS VERSION: JANUARY 2017
}

An electronic version of the paper may be downloaded

- from the SSRN website:

- from the RePEc website:

- from the CESifo website:

www.SSRN.com

Www.RePEc.org

www.CESifo-group.org/wp 


\title{
Unexpected Loan Losses and Bank Capital in an Estimated DSGE Model of the Euro Area
}

\begin{abstract}
We develop a stylized DSGE model in which banks face capital regulation and their loan portfolios are subject to non-diversifiable losses due to aggregate shocks. The framework is used to explore the importance of the interaction between macroeconomic conditions, credit default and bank capitalization for the transmission of macroeconomic shocks. We fit the model to euro area data. Impulse response analysis shows that the aforementioned interaction substantially magnifies the responsiveness of the economy to real and nominal demand side disturbances. The amplification is especially strong with respect to government spending shocks. The model is further capable of replicating two financial market characteristics that are documented in the empirical literature, i.e. the pro-cyclicality of bank profitability and the counter-cyclical response of firm default rates and credit spreads to monetary policy shocks.
\end{abstract}

JEL-Codes: E440, E510, G210, G330.

Keywords: DSGE model, bank capital, aggregate loan losses, business cycle fluctuations.

Nikolay Hristov*

Ifo Institute - Leibniz Institute for

Economic Research

at the University of Munich

Poschingerstrasse 5

Germany-81679 Munich

hristov@ifo.de
Oliver Hülsewig

Munich University of Applied Sciences

Am Stadtpark 20

Germany-81243 Munich

oliver.huelsewig@hm.edu

*corresponding author

October 20, 2016 


\section{Introduction}

Research on the role of banks in the macroeconomy has emphasized the importance of the bank capital channel in shaping business cycle fluctuations (Van den Heuvel, 2002; Kopecky and Van Hoose, 2004; Borio and Zhu, 2012, among others). ${ }^{1}$ For example, a deterioration of macroeconomic conditions typically increases losses in banks' loan portfolios as default rates among private debtors soar. Higher loan losses erode the banks' capital position, which might induce them to reinforce the economic downturn by further tightening credit supply in an attempt to restore desired or regulatory leverage ratios. ${ }^{2}$ This self-reinforcing feedback loop between cyclical macroeconomic conditions and the balance sheet soundness in the banking sector has been repeatedly supposed to have contributed to the depth and persistence of the Great Recession and the European debt crisis. Reducing the likelihood and the severity of this feedback loop is one of the main goals of the stress tests conducted by the European Central Bank (ECB) and the more stringent monitoring and regulation of the banking sector in Europe adopted in recent years. ${ }^{3}$

In this paper, we develop a dynamic stochastic general equilibrium (DSGE) model to quantify the importance of the endogenous interaction between private debtors' default, aggregate loan losses and the bank capital position for the transmission of macroeconomic shocks. The model is estimated using euro area data over the period 2000Q1-2015Q4. Our framework incorporates the assumption that firms producing intermediate goods need to

\footnotetext{
${ }^{1}$ To the best of our knowledge Skander Van den Heuvel was the first who introduced the bank capital channel in the literature. See Van Hoose (2007) or Borio and Zhu (2012) for a survey of recent work on the role of bank capital in monetary transmission.

${ }^{2}$ See Cecchetti and Li (2008), De Graeve et al. (2008), Borio and Zhu (2012) or Gambacorta and Shin (2016) for a description of this or similar mechanisms.

${ }^{3}$ Empirical evidence presented by Hancock and Wilcox (1993), Bernanke and Lown (1991), De Graeve et al. (2008) or Borio and Zhu (2012), among others has documented that individual bank's lending and risk-taking behavior is affected by bank capitalization and capital regulation. Berrospide and Edge (2010) find a quantitatively weaker but still statistically significant link between banks' capital position and lending. However, although these studies deliver valuable insights, they are based on disaggregated data and thus highlight the microeconomic aspects of bank behavior while being silent about a possible endogenous selfreinforcing feedback loop between macroeconomic conditions, loans losses, bank capitalization, lending and aggregate demand.
} 
borrow from banks to finance working capital wherein the loan contract is signed one period in advance. Firms default if, due to idiosyncratic and/or aggregate shocks, their revenue turns to be insufficient to cover the principal and interest payments associated with the loan. Banks can insure themselves against idiosyncratic default risk by building a sufficiently broad loan portfolio. However, the credit contract is not contingent on next period's aggregate state. Accordingly, if the economy-wide default rate increases due to an adverse aggregate shock, banks incur loan losses, which erode their equity capital. Given regulatory restrictions on banks' leverage ratios, the deterioration of the bank capital position adversely affects the real economy by aggravating lending conditions. Empirical evidence supports this mechanism. For example, Tornell and Westermann (2002), Pesaran et al. (2006) and Marcucci and Quagliariello (2009) show that a slump in the economy increases loan losses. In turn, loan losses dampen banks' profits (Bolt et al., 2012), thereby adversely affecting bank capital. The latter gives rise to a tightening of credit conditions (Gambacorta and Shin, 2016), which in turn exacerbates the recession. ${ }^{4}$

Our work fits in the recent literature on monetary DSGE models with credit market frictions and is related to several recent studies. Fiore and Tristani (2013) and Agénor et al. (2014) also assume that firms need to raise loans to fund working capital, but incorporate the idea that loan portfolios are fully insulated from default risk stemming from aggregate shocks. Moreover, they abstract from modelling interactions with bank balance sheets. Christiano et al. (2008), Christiano et al. (2014) and Pesaran and Xu (2011) allow for the possibility of losses in loan portfolios, but also consider a banking sector that operates without equity capital. Meh and Moran (2010), Davis (2010), Dib (2010), Gerali et al.

\footnotetext{
${ }^{4}$ Bolt et al. (2012) find that loan losses are the main driver of the negative impact of economic downturns on bank profit. Depressed bank profit negatively affects bank capital through lower retained earnings. Empirical evidence from Gambacorta and Shin (2016) suggests that lower bank capital is related to higher cost of debt funding, e.g. through deposits, bonds, interbank borrowing, etc., which causes a tightening of credit conditions. Moreover, Pool et al. (2015) show that credit risk measured in terms of loan loss provisioning is an important driver of business cycle fluctuations.
} 
(2010) and Gertler and Karadi (2011) develop models with financial frictions, in which the real and financial sectors are linked through the balance sheets of financial intermediaries, but abstract from unexpected loan losses that adversely affect bank capital. Kollmann et al. (2011) assume that losses in loan portfolios arise from an exogenous stochastic loan default rate. Most closely related to our framework is a series of DSGE models that allow for an endogenous interaction between creditors' default on the one hand and capital accumulation and leverage regulation in the banking sector on the other. In particular, Angeloni and Faia (2013) integrate credit contracts in the style of Diamond and Rajan (2001) into a DSGE model to investigate the potential of cyclical bank capital regulation for macroeconomic stabilization. Benes and Kumhof (2015) modify the financial accelerator proposed in Bernanke et al. (1999) by considering non-contingent financial contracts and explore the welfare properties of simple rules for capital adequacy regulation of banks. In a similar framework, Zhang (2009) discusses the effects of fixed regulatory bank capital ratios for the propagation of technology and monetary shocks. Clerc et al. (2015) develop a real business cycle model in which both, lending to firms for financing new investment as well as mortgage lending to households are conducted through non-state-contingent credit contracts and discuss the transmission of productivity, capital depreciation and bank riskiness shocks.

We make the following contributions to the literature. First, while Angeloni and Faia (2013), Benes and Kumhof (2015), Zhang (2009) and Clerc et al. (2015) calibrate their models to the U.S. economy we estimate a model with endogenous interactions between credit default and bank balance sheets. ${ }^{5}$ Second, we discuss the effects of the interaction between aggregate credit default risk and bank balance sheets by explicitly considering a number of macroeconomic shocks. We identify the contribution of this interaction for the propagation of shocks by comparing the impulse responses generated from our model to

\footnotetext{
${ }^{5}$ Kollmann (2013) also estimates a macroeconomic model with loan losses. However, since his framework is based on the model of Kollmann et al. (2011) loan losses are assumed to arise by an exogenous random amount.
} 
those from alternative model specifications, in which banks' loan portfolios are insulated form aggregate credit default risk.

Our main findings can be summarized as follows. First, the interaction between unexpected losses in banks' loan portfolios and the bank capital position strengthens the effects of real and nominal demand-side shocks. In particular, in the case of disturbances to preferences and monetary policy the amplification regarding the response of aggregate output amounts to about $30 \%$ and $15 \%$, respectively. The government spending multiplier even increases by roughly $40 \%$. The strengthening of the effects arises due to the presence of aggregate loan losses that induce a deterioration of the bank capital position. The decline of bank capital in turn reinforces the tightening of credit conditions. By contrast, alternative specifications of our model in which aggregate lending risk can be completely hedged exhibit a response of bank capital to these shocks that is at least temporarily positive. Second, our model is capable of reproducing two financial market characteristics that are documented in the empirical literature, namely the pro-cyclicality of bank profitability and the counter-cyclical reaction of firm default rates and credit spreads after monetary policy shocks. Alternative specifications of our model in which loan contracts are contingent upon the aggregate state of the economy fail to replicate at least one of these characteristics or even both.

The remainder of the paper is organized as follows. In Section 2 we set out the model. Section 3 presents the results of the estimation of our model. We discuss the data, the calibrated model parameters, the prior assumptions and the posterior estimates. Section 4 summarizes the results of our impulse response analysis. We compare the dynamics of our model to that of alternative models in which loan losses can be fully diversified to explore the role of unexpected losses in banks' loan portfolios for the transmission of macroeconomic shocks. In Section 5 we conclude. 


\section{The model}

We consider a closed economy that consists of final good producers, households, intermediate good producers, capital good producers, banks, a labor union and the government. Intermediate good producers produce differentiated goods by using capital and labor services on which they decide at the end of the previous period after dividend payments to households have been made. We assume that the cost of working capital has to be paid in advance, before any revenues have been realized (Barth and Ramey, 2002). Therefore, intermediate good producers have to take up loans from banks that are extended at a fixed nominal loan rate. In contrast to the standard monetary DSGE model (Smets and Wouters, 2002), our timing of events implies that the nominal loan rate, the nominal capital rental rate and nominal wages for the current period are all determined at the end of the previous period prior to observing current period's shocks. ${ }^{6}$ Capital is rented from competitive capital good producers. Labor is hired from competitive labor packers, which purchase differentiated labor types from the labor union that sets nominal wages.

Intermediate good producers set the prices for their goods and produce in the current period after observing all aggregate shocks. Intermediate goods output is finally determined after the occurrence of idiosyncratic productivity shocks. Solvent firms sell their output to retailers and repay the loan. Insolvent firms declare bankruptcy and pass their output over to the government's insolvency agency that sells it to retailers. Subsequently, the insolvency agency gives the proceeds to the banks after keeping a fraction to cover insolvency proceeding cost. The latter can be thought of comprising court expenses, legal fees and other expenses associated with liquidating a bankrupt firm. Figure 1 summarizes the timing of events.

We assume that banks cannot insure their loan portfolios from aggregate risk. The reason is twofold. First, the terms of a loan contract, i.e. the nominal loan volume and

\footnotetext{
${ }^{6}$ Christiano and Eichenbaum (1992), Christiano et al. (1997) or Christiano et al. (2005) adopt a similar timing assumption with respect to factor input, pricing and production decisions.
} 
Figure 1: Timing of events determine input demands for production in period $t+1$

- Capital is rented from capital good producers at fixed nominal capital rental rate and paid in advance

- Union sells labor to labor packers after setting nominal wages for period $t+1$

- Labor is hired from labor packers at fixed nominal wage and paid in advance

- Intermediate good producers ask banks for loans to finance working capital in advance. Loan rate is set on basis of expected default in period $\mathrm{t}+1$

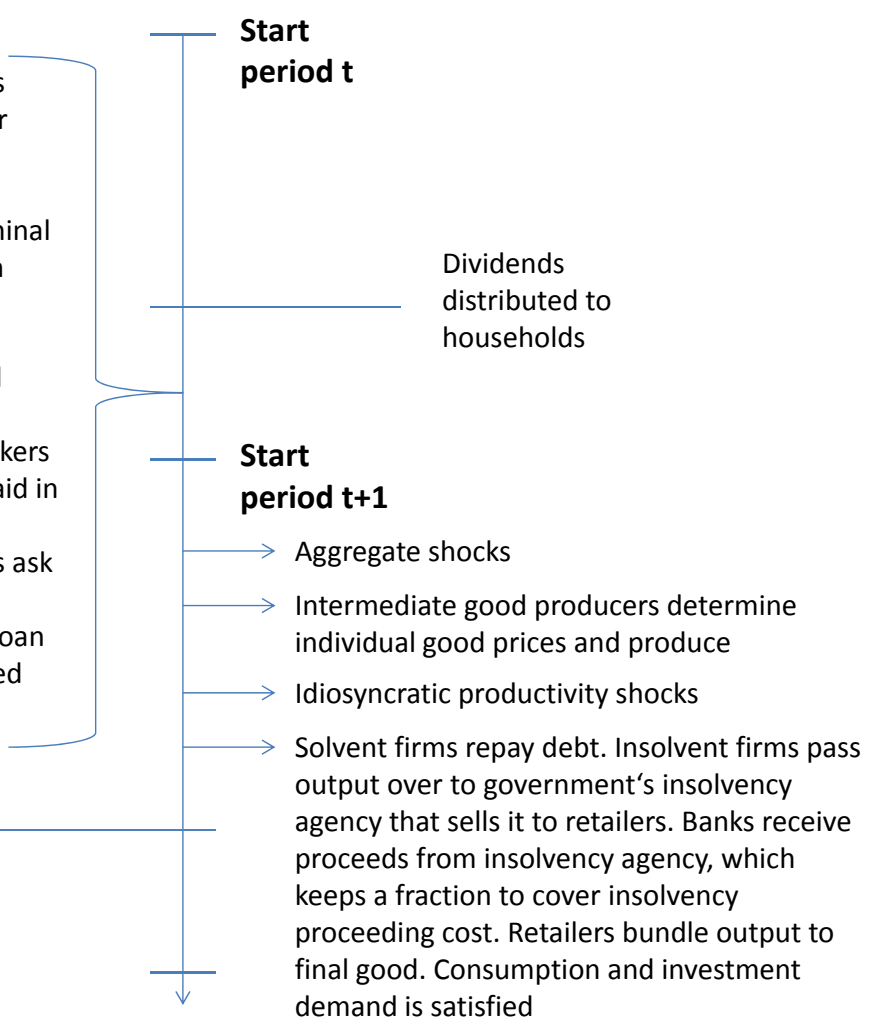

Dividends distributed to households 
loan rate, have to be fixed before observing the realization of aggregate shocks. Second, access to state contingent financial contracts is ruled out. Accordingly, banks' profit is reduced by unexpected loan losses which in turn deteriorates the banks' capital position. In addition, we assume that banks face costs if their capital-to-loan ratio, i.e. the inverse of leverage, deviates from an exogenous target value. Following Gerali et al. (2010) these costs are supposed to be quadratic and reflect the trade-off between seeking to avoid the violation of the minimum capital adequacy regulation and the attempt to operate with a higher leverage. Once the capital-to-loan ratio falls below the target value the loan rate raises, thereby adversely affecting the real economy.

\subsection{Households}

There is a continuum of households indexed by $i \in(0,1)$. Every household represents a family that consists of entrepreneurs, bankers and workers. Entrepreneurs manage firms that produce either final goods, intermediated goods or capital goods. Bankers manage a financial intermediary. Finally, workers earn income from supplying heterogenous labour.

Expected lifetime utility of the representative household $i$ is given by:

$$
E_{0} \sum_{t=0}^{\infty} \beta^{t}\left[\frac{Z_{t}^{c}\left(C_{t}(i)-H_{t}\right)^{1-\sigma}}{1-\sigma}-\frac{\xi_{N} N_{t}^{1+\eta}(i)}{1+\eta}\right],
$$

where $C_{t}(i)$ is a consumption basket, which consists of differentiated consumption goods, $H_{t}$ denotes external habits, $\beta$ is the discount factor, $\sigma$ is the coefficient of relative risk aversion, $Z_{t}^{c}$ is a preference shock, $N_{t}(i)$ is hours worked in period $t+1$, which however are determined in labour contracts signed at end of period $t, \eta$ is the elasticity of marginal disutility of labor and $\xi_{N}$ is a scaling parameter. Habits are assumed to depend positively on aggregate consumption in period $t-1$, i.e. $H_{t}=h C_{t-1}$, where $h \in(0,1)$.

Household $i$ maximizes its expected lifetime utility subject to the intertemporal budget 
constraint:

$$
\begin{aligned}
P_{t} C_{t}(i)+D_{t}(i)= & W_{t-1}(i) N_{t-1}(i)+R_{t-1}^{D} D_{t-1}(i)+P_{t} \Pi_{t}^{\text {Firms }}(i) \\
& +P_{t} \Upsilon_{t}(i)-P_{t} U_{t}(i)-P_{t} T_{t}(i)+P_{t} \Omega_{t}(i),
\end{aligned}
$$

where $P_{t}$ is the consumer price index, $D_{t}(i)$ are deposit holdings at banks, $R_{t}^{D}$ is the gross deposit rate, $W_{t}(i)$ is the nominal wage, $w_{t}(i)=W_{t}(i) / P_{t}$ is the real wage, $\Pi_{t}=P_{t} / P_{t-1}$ is gross inflation, $\Pi_{t}^{\text {Firms }}(i)$ are dividends distributed by firms, i.e. intermediate good producers and capital good producers, $\Upsilon_{t}(i)$ are net lump-sum incomes distributed by banks, $U_{t}(i)$ is a lump-sum fee transferred to the union, $T_{t}(i)$ is a lump-sum tax and $\Omega_{t}(i)$ denotes a net cash flow distributed by a clearing house. ${ }^{7}$ The first-order conditions with respect to $C_{t}(i)$ and $D_{t}(i)$ are:

$$
\begin{aligned}
\lambda_{t}(i) & =Z_{t}^{c}\left(C_{t}(i)-H_{t}\right)^{-\sigma} \\
\lambda_{t}(i) & =\beta E_{t}\left[\lambda_{t+1}(i) \frac{R_{t}^{D}}{\Pi_{t+1}}\right],
\end{aligned}
$$

where $\lambda_{t}(i)$ is the Lagrange multiplier of the budget constraint. Since all households behave identically we can subsequently drop the index $i$.

\subsection{Nominal wage setting}

The union collects differentiated labor types from workers and sells these types to competitive labor packers after setting nominal wages $W_{t}(i)$. The latter become effective in

\footnotetext{
${ }^{7}$ We assume that banks transfer the loans extended to intermediate good producers to a clearing house at the end of every period. The clearing house is an independent non-optimizing agency, which in turn distributes the wage payments to households and the payments associated with the renting of capital to the capital good producers at the beginning of the next period.
} 
period $t+1 .^{8}$ The demand of labor packers for labor type $i$ is:

$$
N_{t}(i)=\left(\frac{W_{t}(i)}{W_{t}}\right)^{-\phi_{t}} N_{t}
$$

where $N_{t}=\left[\int_{0}^{1} N_{t}^{\frac{\phi_{t}-1}{\phi_{t}}}(i) d i\right]^{\frac{\phi_{t}}{\phi_{t}-1}}$ is aggregate labor, $W_{t}=\left[\int_{0}^{1} W_{t}^{1-\phi_{t}}(i) d i\right]^{\frac{1}{1-\phi_{t}}}$ is the aggregate nominal wage and $\phi_{t}$ is the stochastic elasticity of substitution between the different types of labor. Labor packers and intermediate good firms sign labor contracts at the end of period $t$ in which the amount of working hours used for producing of intermediate goods in $t+1$ is specified.

We assume that the union sets nominal wages for its members to maximize their utility subject to labor demand (5) and wage adjustment cost, which are covered by charging every member a lump-sum fee. The intertemporal maximization problem for labor type $i$ can be stated as:

$$
\begin{aligned}
& \max _{N_{t}(i) W_{t}(i)} E_{0} \sum_{t=0}^{\infty} \beta^{t}\left\{\lambda_{t}\left[\frac{W_{t-1}(i)}{P_{t-1}} \frac{P_{t-1}}{P_{t}} N_{t-1}(i)-\frac{\vartheta}{2}\left(\frac{W_{t}(i)}{W_{t-1}(i)}-1\right)^{2} \frac{W_{t}}{P_{t}}\right]\right. \\
&\left.-\xi_{N} \frac{N_{t}^{1+\eta}(i)}{1+\eta}\right\} \\
& \text { s.t. } \quad N_{t}(i)=\left(\frac{W_{t}(i)}{W_{t}}\right)^{-\phi_{t}} N_{t},
\end{aligned}
$$

where $\vartheta$ is the wage adjustment cost parameter. The first-order conditions of the intertem-

\footnotetext{
${ }^{8}$ The idea of nominal wage setting one period in advance is discussed in Gray (1978) and incorporated in a DSGE framework by Cho and Cooley (1995) and Benassy (1995), among others. Similar to our approach, these papers consider nominal wage contracts in which firms and households agree in the current period on the nominal wage to be paid in a subsequent period, which however is not necessarily the following period. Firms choose labor hours each period. In contrast, households give up the right to determine labor hours by agreeing to the nominal contract wage.
} 
poral maximization problem are:

$$
\begin{aligned}
& \xi_{N} N_{t}^{\eta}(i)=\beta E_{t}\left[\lambda_{t+1}(i) \frac{W_{t}(i)}{P_{t}} \frac{P_{t}}{P_{t+1}}-m r s_{t+1}(i)\right] \\
& \vartheta \lambda_{t}\left(\frac{W_{t}(i)}{W_{t-1}(i)}-1\right) \frac{W_{t}}{P_{t}} \frac{1}{W_{t-1}(i)}= \\
& \beta E_{t}\left[\lambda_{t+1}(i)\left[\frac{N_{t}(i)}{P_{t+1}}-\vartheta\left(\frac{W_{t+1}(i)}{W_{t}(i)}-1\right) \frac{W_{t+1}}{P_{t+1}}\left(\frac{W_{t+1}(i)}{\left(W_{t}(i)\right)^{2}}\right)\right]\right. \\
& \left.\quad-\phi_{t} m r s_{t+1}(i)\left(\frac{W_{t}(i)}{W_{t}}\right)^{-\phi_{t}-1} \frac{N_{t}}{W_{t}}\right],
\end{aligned}
$$

where $m r s_{t}(i)$ is the marginal rate of substitution. Thus, nominal wage inflation in a symmetric equilibrium is determined by:

$$
\begin{aligned}
\vartheta\left(\Pi_{t}^{W}-1\right) \Pi_{t}^{W}= & \vartheta \beta E_{t}\left[\frac{\lambda_{t+1}}{\lambda_{t}}\left(\Pi_{t+1}^{W}-1\right) \frac{\left(\Pi_{t+1}^{W}\right)^{2}}{\Pi_{t+1}}\right] \\
& +E_{t}\left[\left(1-\phi_{t}\right) \beta \frac{\lambda_{t+1}}{\lambda_{t}} \frac{N_{t}}{\Pi_{t+1}}+\frac{\phi_{t} \xi_{N} N_{t}^{1+\eta}}{\lambda_{t} w_{t}}\right]
\end{aligned}
$$

where $\Pi_{t}^{W}=W_{t} / W_{t-1}$ is gross nominal wage inflation. Finally, the real wage evolves according to:

$$
w_{t}=\frac{w_{t-1} \Pi_{t}^{W}}{\Pi_{t}}
$$

In the special case of no convex wage adjustment costs, i.e. $\vartheta=0$, nominal wage setting is governed by the following condition:

$$
\frac{\phi_{t}}{\phi_{t}-1} \xi_{N} N_{t}^{\eta}=\beta E_{t}\left[\frac{\lambda_{t+1}}{\Pi_{t+1}}\right] w_{t},
$$

which shows that aggregate nominal shocks, e.g. due to interventions by the central bank, can still have real effects. For instance, a monetary policy disturbance distorts the labor supply decision by affecting expected next period inflation, which has consequences for other real aggregates. Consequently, the assumption that wages are set one period in advance, induces an additional channel of monetary policy transmission that is operative even in absence of wage adjustment costs or other types of nominal rigidities. This source of monetary 
non-neutrality is similar to the one arising as a result of nominal debt contracts. ${ }^{9}$

\subsection{Capital good producers}

Capital good producers are competitive. They rent capital to intermediate good producers at the end of period $t$ for which they receive a payment that is used to purchase investment goods in the consecutive period.

Expected nominal profit flow of capital good producers is given by:

$$
E_{0} \sum_{t=0}^{\infty} \beta^{t} \frac{\lambda_{t+1}}{\lambda_{0}} \frac{P_{0}}{P_{t+1}}\left[R_{t-1}^{K} K_{t-1}-P_{t} I_{t}-\frac{\kappa}{2}\left(\frac{Z_{t}^{i} I_{t}}{I_{t-1}}-1\right)^{2} P_{t} I_{t}\right] \text {, }
$$

where $K_{t}$ denotes the capital stock, $R_{t}^{K}$ is the nominal capital rental rate, $I_{t}$ is investment activities and $Z_{t}^{i}$ is a shock to the efficiency of investment. We assume that changes in investment activities are related to investment adjustment cost (Christiano et al., 2005), where $\kappa$ denotes the investment adjustment cost parameter. The capital stock evolves according to:

$$
K_{t}=I_{t}+(1-\delta) K_{t-1}
$$

where $\delta$ is the capital depreciation rate. Restating expected profit flow in real terms and maximizing it with respect to $K_{t+1}$ and $I_{t}$ subject to (11) gives the following first-order conditions:

$$
\begin{aligned}
\beta E_{t}\left[\frac{\lambda_{t+1}}{\lambda_{t}} \frac{z_{t}}{\Pi_{t+1}}\right]= & \gamma_{t}-\beta E_{t}\left[\frac{\lambda_{t+1}}{\lambda_{t}} \gamma_{t+1}\right](1-\delta) \\
\gamma_{t}= & 1+\kappa\left(\frac{Z_{t}^{i} I_{t}}{I_{t-1}}-\delta\right) \frac{Z_{t}^{i} I_{t}}{I_{t-1}}+\frac{\kappa}{2}\left(\frac{Z_{t}^{i} I_{t}}{I_{t-1}}-1\right)^{2} \\
& -\beta E_{t}\left[\frac{\lambda_{t+1}}{\lambda_{t}} \kappa\left(\frac{Z_{t+1}^{i} I_{t+1}}{I_{t}}-1\right) Z_{t+1}^{i}\left(\frac{I_{t+1}}{I_{t}}\right)^{2}\right],
\end{aligned}
$$

where $z_{t}$ is the real capital rental rate, i.e. $z_{t}=R_{t}^{K} / P_{t}$, and $\gamma_{t}$ is the Lagrange multiplier attached to the law of motion for capital (11).

\footnotetext{
${ }^{9}$ See Garriga et al. (2016) for a discussion and also the references cited therein.
} 


\subsection{Final good producers}

Final good producers operate under perfect competition. The technology to produce the aggregate final good is:

$$
Y_{t}=\left[\int_{0}^{1}\left(\omega_{t}^{\frac{1}{\xi_{t}}}(j) Y_{t}^{\frac{\xi_{t}-1}{\xi_{t}}}(j)\right) d j\right]^{\frac{\xi_{t}}{\xi_{t}-1}}
$$

where $Y_{t}$ is the final good, $Y_{t}(j)$ are intermediate goods indexed by $j \in(0,1), \omega_{t}(j)$ is the share associated with the output level of good $j$ and $\xi_{t}$ is the stochastic elasticity of substitution between the different types of goods.

Profit maximization by final good producers leads to the following demand equation for each intermediate good:

$$
Y_{t}(j)=\omega_{t}(j)\left(\frac{P_{t}(j)}{P_{t}}\right)^{-\xi_{t}} Y_{t}
$$

where $P_{t}=\left[\int_{0}^{1}\left(\omega_{t}(j) P_{t}^{1-\xi_{t}}(j)\right) d j\right]^{\frac{1}{1-\xi_{t}}}$ is the price of the final good and $P_{t}(j)$ is the price of intermediate good $j$.

\subsection{Intermediate good producers}

Intermediate good producers indexed by $j \in(0,1)$ produce differentiated goods in an environment of monopolistic competition. Intermediate good producer $j$ has access to the technology:

$$
\begin{aligned}
Y_{t+1}(j) & =Z_{t+1}^{a} \omega_{t+1}(j) K_{t}^{\alpha}(j) N_{t}^{1-\alpha}(j) \\
& =\omega_{t+1}(j) \tilde{Y}_{t+1}(j)
\end{aligned}
$$

where $Z_{t+1}^{a}$ is an aggregate productivity shock and $\omega_{t+1}(j)$ is an idiosyncratic productivity shock. Intermediate good producers borrow from banks to cover their cost of working capital at the end of period $t$. Let $L_{t}(j)$ denote the nominal loan volume, then the financing constraint in real terms is:

$$
L_{t}^{R}(j)=z_{t} K_{t}(j)+w_{t} N_{t}(j)
$$


where $L_{t}^{R}(j)=L_{t}(j) / P_{t}$. Banks extend loans at gross nominal loan rate $R_{t}^{L}$. As in Agénor et al. (2014) we assume that the idiosyncratic productivity shock $\omega_{t}(j)$ is serially uncorrelated and drawn from a uniform distribution with $(\underline{\omega}, \bar{\omega})$ lower and upper bounds. ${ }^{10}$

Expected real marginal cost. Intermediate good producer $j$ seeks to minimize expected real production cost for period $t+1$ by choosing optimal capital and labor services at end of period $t$ subject to the technological restriction arising from the production function. The Lagrangian for this minimization problem is:

$$
\begin{aligned}
\min _{K_{t}(j), N_{t}(j)} E_{S_{t+1}, \omega \mid t}\left[\beta \frac { \lambda _ { t + 1 } } { \lambda _ { t } } \left(\frac{z_{t} R_{t}^{L} K_{t}(j)}{\Pi_{t+1}}+\frac{w_{t} R_{t}^{L} N_{t}(j)}{\Pi_{t+1}}\right.\right. \\
\left.\left.\quad-m c_{t+1}(j)\left(Z_{t+1}^{a} \omega_{t+1}(j) K_{t}^{\alpha}(j) N_{t}^{1-\alpha}(j)-Y_{t+1}(j)\right)\right)\right]
\end{aligned}
$$

where $E_{S_{t+1}, \omega \mid t}$ is the expectation operator and $m c_{t}(j)$ is the Lagrange multiplier. The expectation operator reflects expectations at end of period $t$ regarding the next period's aggregate state $S_{t+1}$ and idiosyncratic productivity shock $\omega_{t+1}(j)$, wherein the latter's distribution is by assumption identical across firms. Hence, expectations are built over the joint distribution of $\left(S_{t+1}, \omega_{t+1}\right)$. Note that in (18) the only variables which depend stochastically on $\omega_{t+1}(j)$ are $Y_{t+1}(j)$ and $m c_{t+1}(j)$. Further, since by assumption $\omega_{t}(j)$ is i.i.d., its distribution is time invariant. Minimizing expected real production cost gives the following input demands for capital and labor after adopting the law of iterated expectations:

$$
\begin{aligned}
& \beta E_{t}\left[\frac{\lambda_{t+1}}{\lambda_{t}} \frac{z_{t} R_{t}^{L}}{\Pi_{t+1}}\right]= \\
& \alpha\left(\frac{N_{t}(j)}{K_{t}(j)}\right)^{1-\alpha} \beta E_{t}\left[\frac{\lambda_{t+1}}{\lambda_{t}} Z_{t+1}^{a} E_{\omega}\left[m c_{t+1}(j) \omega_{t+1}(j)\right]\right]
\end{aligned}
$$

\footnotetext{
${ }^{10}$ The uniform distribution is the same for all intermediate good firms.
} 


$$
\begin{aligned}
& \beta E_{t}\left[\frac{\lambda_{t+1}}{\lambda_{t}} \frac{w_{t} R_{t}^{L}}{\Pi_{t+1}}\right]= \\
& (1-\alpha)\left(\frac{N_{t}(j)}{K_{t}(j)}\right)^{-\alpha} \beta E_{t}\left[\frac{\lambda_{t+1}}{\lambda_{t}} Z_{t+1}^{a} E_{\omega}\left[m c_{t+1}(j) \omega_{t+1}(j)\right]\right],
\end{aligned}
$$

where $E_{\omega}$ denotes expectations over the distribution of $\omega_{t+1}(j)$ while $E_{t}$ reflects expectations over the possible aggregate states.

In what follows, we assume a symmetric equilibrium in the intermediate goods sector, i.e. firms are identical regarding their optimal factor demands as well as pricing decisions. ${ }^{11}$ Consequently, in each period, the expectation value $E_{\omega}\left[m c_{t}(j) \omega_{t}(j)\right]$ is the same across all firms. Accordingly, for all firms we have:

$$
\tilde{Y}_{t}(j)=\tilde{Y}_{t}, \quad \forall j
$$

where $\tilde{Y}_{t}=Z_{t}^{a} K_{t-1}^{\alpha} N_{t-1}^{1-\alpha}$ is the aggregate production in the intermediate sector.

Further, as evident from (19) and (20) optimal demands for capital and labor depend on expected inflation $E_{t}\left[\Pi_{t+1}\right]$. Similarly to the households' labor supply decision in Section 2.2, this again reflects the fact that nominal factor payments are fixed one period in advance. This

\footnotetext{
${ }^{11}$ If one assumes perfectly flexible prices in our model, then, in order to prove symmetry across firms in the intermediate goods sector, it would be sufficient to impose that the starting values of labor $N_{-1}(j)$ and capital $K_{-1}(j)$ in period $t=-1$ are the same for all firms. In particular, the solutions for firm specific capital and labor input as well as pricing can be derived analytically and read:

$$
\begin{gathered}
K_{t}(j)=\left[\frac{\theta}{\theta-1} \frac{E_{t}\left[\beta \frac{\lambda_{t+1}}{\lambda_{t}} \frac{1}{\Pi_{t+1}}\right]}{E_{t}\left[\beta \frac{\lambda_{t+1}}{\lambda_{t}}\left(\frac{Z_{t+1}^{a}}{Y_{t+1}}\right)^{-\frac{1}{\xi_{t}}}\right]} \frac{\left(z_{t} R_{t}^{L}\right)^{1+\left(\xi_{t}-1\right) \alpha}}{\left(w_{t} R_{t}^{L}\right)^{\left(\xi_{t}-1\right) \alpha}}\right]^{-\xi_{t}}, \\
N_{t}(j)=\frac{z_{t}}{w_{t}} K_{t}(j) \\
\frac{P_{t}(j)}{P_{t}}=\left(\frac{Z_{t}^{a} N_{t-1}^{1-\alpha}(j) K_{t-1}^{\alpha}(j)}{Y_{t}}\right)^{-\frac{1}{\xi_{t}}}
\end{gathered}
$$

where $Y_{t}$ is aggregate output. In the case of convex price adjustment costs as specified in this paper, one also needs to assume that the relative price $P_{-1}(j) / P_{-1}$ is the same across firms. Given the symmetry regarding period $t=-1$, one can show that the behavior of firms is approximately - up to a linear approximation identical.
} 
introduces an additional channel of monetary policy transmission which operates provided the interventions of the central bank are sufficiently persistent to induce movements in expected inflation.

Price setting. Intermediate good producer $j$ sets the price for its good in every period to maximize the expected discounted real profit flow before the realization of the idiosyncratic productivity shock $\omega_{t}(j)$. The maximization is subject to the expected demand for good j. Following Rotemberg (1984) we assume that price changes are costly and incorporate quadratic price adjustment cost.

Given the demand function (15), the maximization problem can be stated as:

$$
\begin{aligned}
\max _{\left\{P_{t}(j)\right\}_{t=0}^{\infty}} E_{0} \sum_{t=0}^{\infty} \beta^{t} \frac{\lambda_{t+1}}{\lambda_{0}} & \left\{E_{\omega}\left[\frac{P_{t}(j)}{P_{t}} \omega_{t}(j)\left(\frac{P_{t}(j)}{P_{t}}\right)^{-\xi_{t}} Y_{t}\right]-\frac{z_{t-1} R_{t-1}^{L} K_{t-1}(j)}{\Pi_{t}}\right. \\
& -\frac{w_{t-1} R_{t-1}^{L} N_{t-1}(j)}{\Pi_{t}}-\frac{\theta}{2}\left(\frac{P_{t}(j)}{P_{t-1}(j)}-1\right)^{2} Y_{t} \\
& \left.+E_{\omega}\left[m c_{t}(j)\left(\omega_{t}(j) \tilde{Y}_{t}(j)-\omega_{t}(j)\left(\frac{P_{t}(j)}{P_{t}}\right)^{-\xi_{t}} Y_{t}\right)\right]\right\},
\end{aligned}
$$

where $\theta$ is the price adjustment cost parameter. The first-order condition is:

$$
\begin{aligned}
E_{\omega}[ & -\xi_{t} \omega_{t}(j)\left(\frac{P_{t}(j)}{P_{t}}\right)^{-\xi_{t}-1} \frac{P_{t}(j)}{P_{t}} \frac{Y_{t}}{P_{t}} \\
& +\omega_{t}(j)\left(\frac{P_{t}(j)}{P_{t}}\right)^{-\xi_{t}} \frac{Y_{t}}{P_{t}}-\theta\left(\frac{P_{t}(j)}{P_{t-1}(j)}-1\right) \frac{Y_{t}}{P_{t-1}(j)} \\
& \left.+\xi_{t} m c_{t}(j) \omega_{t}(j)\left(\frac{P_{t}(j)}{P_{t}}\right)^{-\xi_{t}-1} \frac{Y_{t}}{P_{t}}\right] \\
+ & \theta \beta E_{t}\left[\frac{\lambda_{t+1}}{\lambda_{t}}\left(\frac{P_{t+1}(j)}{P_{t}(j)}-1\right) Y_{t+1}\left(\frac{P_{t+1}(j)}{P_{t}^{2}(j)}\right)\right]=0 .
\end{aligned}
$$

If intermediate good producers chose identical $K_{t}(j)$ and $N_{t}(j)$, they all set the same price, which allows us to drop index $j$. Thus, the inflation rate in a symmetric equilibrium is given 
by:

$$
\begin{aligned}
\theta \Pi_{t}\left(\Pi_{t}-1\right)= & \theta \beta E_{t}\left[\frac{\lambda_{t+1}}{\lambda_{t}} \Pi_{t+1}\left(\Pi_{t+1}-1\right) \frac{Y_{t+1}}{Y_{t}}\right] \\
& +\left(1-\xi_{t}\right) E_{\omega}[\omega(j)]+\xi_{t} E_{\omega}\left[m c_{t}(j) \omega(j)\right],
\end{aligned}
$$

where $E_{\omega}\left[m c_{t}(j) \omega_{t}(j)\right]$ denotes expected real marginal cost and expectations are taken with respect to the distribution of possible idiosyncratic productivity levels $\omega$. Recall that this distribution is identical across firms and time invariant.

Cutoff point. Intermediate good producer $j$ declares default in period $t+1$ if its revenue after the realization of the idiosyncratic productivity shock is not high enough to cover cost, where the latter comprise the cost of borrowing and the cost of price adjustment. Consequently, default occurs if:

$$
P_{t+1}(j) Y_{t+1}(j)<R_{t}^{L} L_{t}(j)+\frac{\theta}{2}\left(\frac{P_{t+1}(j)}{P_{t}(j)}-1\right)^{2} P_{t+1} Y_{t+1}
$$

or

$$
\omega_{t+1}(j) \tilde{Y}_{t+1}(j)<\frac{R_{t}^{L} L_{t}(j)}{P_{t+1}(j)}+\frac{\theta}{2}\left(\frac{P_{t+1}(j)}{P_{t}(j)}-1\right)^{2} \frac{P_{t+1} Y_{t+1}}{P_{t+1}(j)}
$$

We denote the cutoff point below which firm $j$ defaults by $\tilde{\omega}_{t}(j)$, i.e. the cutoff point is the value of $\omega_{t}(j)$ for which $(22)$ holds with equality. Thus, in a symmetric equilibrium we get:

$$
\tilde{\omega}_{t}=\frac{R_{t-1}^{L} L_{t-1}^{R}}{\Pi_{t} \tilde{Y}_{t}}+\frac{\theta}{2}\left(\Pi_{t}-1\right)^{2} .
$$

Since intermediate good producers set the same price in a symmetric equilibrium, the cutoff point is identical for all of them, i.e. $\tilde{\omega}=\tilde{\omega}(j), \forall t$. In the financial accelerator framework of Bernanke et al. (1999) banks would know $\tilde{\omega}_{t+1}$ when specifying the loan contract. In contrast, in our framework this happens on the basis of expectations about $\tilde{\omega}_{t+1}$. Finally, (23) also shows that fluctuations in current inflation affect the aggregate probability of default. This is a direct manifestation of the Fisher debt deflation effect also discussed in Christiano et al. 
(2010): since interest and principal payments on the loan are fixed in nominal terms one period in advance, a sudden decline in inflation elevates the real debt burden relative to the real value of a firm's revenue. Moreover, the transmission of monetary policy is enriched by an additional channel via (23).

\subsection{Banks}

Banks are competitive. They extend loans to intermediate good producers, accept deposits from households on which they are obliged to hold minimum reserves, access central bank credit and borrow or lend on the interbank money market. The capital endowment of every bank at the end of period $t$ is $E Q_{t}$.

Expected profit of the representative bank is given by:

$$
\begin{aligned}
E_{t}\left[\Pi_{t+1}^{\text {Bank }}\right]= & E_{t}\left[\mathcal{R}_{t+1}\right]-R_{t}^{D} D_{t}-R_{t}\left(B_{t}-M R_{t}\right) \\
& -\frac{\zeta}{2}\left(\frac{E Q_{t}}{L_{t}}-\nu\right)^{2} E Q_{t}
\end{aligned}
$$

where $E_{t}\left[\mathcal{R}_{t+1}\right]$ is the expected return from lending $L_{t}$, i.e. $L_{t}=\int_{0}^{1} L_{t}(j) d j$ at gross nominal loan rate $R_{t}^{L}, D_{t}$ are deposits, $R_{t}^{D}$ is the gross nominal deposit rate, $B_{t}$ denotes central bank credit, $M R_{t}$ denotes minimum reserve holdings: $M R_{t}=r D_{t}$, where $r \in(0,1)$ is the minimum reserve ratio, and $R_{t}$ is the gross nominal policy rate. Minimum reserve holdings are remunerated at rate $R_{t}$. Following Gerali et al. (2010) we assume that every bank faces a cost related to its capital position $E Q_{t}$. The cost emerges whenever the capital-to-loan ratio $E Q_{t} / L_{t}$ diverges from the target value $\nu$, where $\zeta$ denotes the capital adjustment cost parameter. Moreover, we assume that the access to central bank credit is unlimited, which means by arbitrage that the deposit rate equals the policy rate (Freixas and Rochet, 1997), i.e. $R_{t}^{D}=R_{t}$.

The bank's balance sheet at the end of period $t$ is:

$$
L_{t}+M R_{t}=D_{t}+B_{t}+E Q_{t}
$$


A single bank takes its deposit level as given and adjusts its position on the interbank money market in accordance to deposit inflows or outflows to meet the balance sheet constraint. Thus, for a single bank $B_{t}$ can be either positive or negative depending on whether it borrows $\left(B_{t}>0\right)$ or lends $\left(B_{t}<0\right)$ on net. However, for the representative bank $B_{t}$ corresponds to the amount of central bank credit that is needed to fulfill the minimum reserve requirement (Hülsewig et al., 2006).

Maximization of expected profit. The representative bank maximizes its expected profit (24) by choosing optimal loan supply subject to the balance sheet constraint (25) and equity endowment $E Q_{t}$. Expected return from lending to intermediate good producer $j$ is given by:

$$
\begin{aligned}
E_{t}\left[\mathcal{R}_{t+1}(j)\right]= & \int_{\tilde{\omega}_{t+1}(j)}^{\bar{\omega}} R_{t}^{L} L_{t}(j) f\left(\omega_{t+1}(j)\right) d \omega_{t+1}(j) \\
+ & \int_{\underline{\omega}}^{\tilde{\omega}_{t+1}(j)}\left(P_{t+1}(j) Y_{t+1}(j)-\frac{\theta}{2}\left(\frac{P_{t+1}(j)}{P_{t}(j)}-1\right)^{2} P_{t+1} Y_{t+1}\right. \\
& \left.\quad(1-\chi) P_{t+1}(j) Y_{t+1}(j)\right) f\left(\omega_{t+1}(j)\right) d \omega_{t+1}(j),
\end{aligned}
$$

where $(1-\chi)$ denotes the fraction of the borrower's output that is taken by the government's insolvency agency to cover the insolvency proceedings cost, where $\chi \in(0,1)$, and $f\left(\omega_{t+1}(j)\right)$ is the density function of $\omega_{t+1}(j)$. The bounds of integration are $\bar{\omega}$ and $\underline{\omega}$. Restating (26) 
gives:

$$
\begin{aligned}
E_{t}\left[\mathcal{R}_{t+1}(j)\right]= & R_{t}^{L} L_{t}(j) \\
& -E_{t} \int_{\underline{\omega}}^{\tilde{\omega}_{t+1}(j)}\left[R_{t}^{L} L_{t}(j)-\left(\chi P_{t+1}(j) Y_{t+1}(j)\right.\right. \\
& \left.\left.-\frac{\theta}{2}\left(\frac{P_{t+1}(j)}{P_{t}(j)}-1\right)^{2} P_{t+1} Y_{t+1}\right)\right] f\left(\omega_{t+1}(j)\right) d \omega_{t+1}(j) \\
= & R_{t}^{L} L_{t}(j)-L_{t}(j) E_{t}\left[\frac{P_{t+1}(j) \tilde{Y}_{t+1}(j)}{L_{t}(j)}\right. \\
& \left.\times \int_{\underline{\omega}}^{\tilde{\omega}_{t+1}(j)}\left[\tilde{\omega}_{t+1}(j)-\chi \omega_{t+1}(j)\right] f\left(\omega_{t+1}(j)\right) d \omega_{t+1}(j)\right] .
\end{aligned}
$$

Since all intermediate good producers are identical ex ante they all obtain the same loan, which allows us to drop index $j$ subsequently.

Maximizing expected profit in real terms leads to the following first-order condition:

$$
R_{t}^{L}=R_{t}-\zeta\left(\frac{E Q_{t}^{R}}{L_{t}^{R}}-\nu\right)\left(\frac{E Q_{t}^{R}}{L_{t}^{R}}\right)^{2}+\rho_{t}^{L}
$$

where $E Q_{t}^{R}$ is real bank capital, i.e. $E Q_{t} / P_{t}$, and $\rho_{t}^{L}$ is the finance premium that is given by:

$$
\rho_{t}^{L}=E_{t}\left[\frac{\prod_{t+1} Y_{t+1}}{L_{t}^{R}} \int_{\underline{\omega}}^{\tilde{\omega}_{t+1}}\left(\tilde{\omega}_{t+1}-\chi \omega_{t+1}\right) f\left(\omega_{t+1}\right) d \omega_{t+1}\right] .
$$

The first-order condition (28) states that the bank's loan rate is equal to the policy rate that determines marginal refinancing cost plus the marginal cost associated with managing the capital-to-asset ratio and the finance premium that compensates for expected loan losses. Under the assumption of a uniform distribution of the idiosyncratic productivity shock over the interval $(\underline{\omega}, \bar{\omega})$, the probability density of $\omega_{t}(j)$ is $1 /(\bar{\omega}-\underline{\omega})$ and its mean $E_{\omega}\left[\omega_{t}(j)\right]=$ $(\bar{\omega}-\underline{\omega}) / 2$. Thus, the finance premium simplifies to:

$$
\rho_{t}^{L}=E_{t}\left[\frac{\prod_{t+1} Y_{t+1}}{L_{t}^{R}} \quad \frac{(2-\chi) \tilde{\omega}_{t+1}^{2}-\underline{\omega}\left(2 \tilde{\omega}_{t+1}-\chi \underline{\omega}\right)}{2(\bar{\omega}-\underline{\omega})}\right] .
$$

The finance premium is determined by the expected ratio between the value of output 
received in case of default and the outstanding loan amount as well as the degree of crosssectional uncertainty in the economy.

Development of bank capital. Real capital of the representative bank at the end of period $t+1$ is given by:

$$
\begin{aligned}
E Q_{t+1}^{R} \Pi_{t+1}= & L_{t}^{R}\left(\bar{R}_{t+1}^{L}-R_{t}\right)+R_{t} E Q_{t}^{R} \\
& -\frac{\zeta}{2}\left(\frac{E Q_{t}^{R}}{L_{t}^{R}}-\nu\right)^{2} E Q_{t}^{R} \\
& -\Upsilon_{t+1}+Z_{t+1}^{e},
\end{aligned}
$$

where $\bar{R}_{t+1}^{L}$ is the actual rate of return from lending that is realized after the occurrence of all shocks in period $t+1, \Upsilon_{t+1}$ are real dividends paid to households, and $Z_{t+1}^{e}$ is a shock to bank capital. We assume that $\Upsilon_{t+1}=v E Q_{t+1}^{R}$ (Benes and Kumhof, 2015), where $v \in(0,1)$. The actual rate of return from lending is:

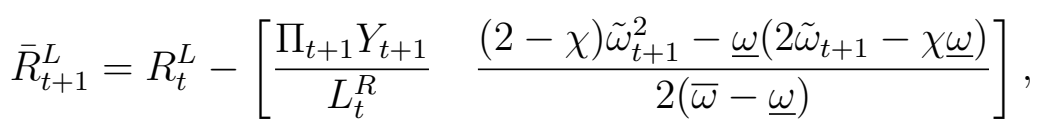

which shows that the rate of return on lending is determined by the difference between the loan rate that is fixed ex ante and the actual rate of return that is realized after loan losses. Therefore, in contrast to the standard financial accelerator (e.g. Bernanke et al., 1999), the risk of lending is non-diversifiable because the loan rate is not contingent on the realization of aggregate shocks.

\subsection{Monetary policy, government spending and goods market clearing}

The central bank sets the policy rate according to:

$$
R_{t}=R^{1-\phi_{R}} R_{t-1}^{\phi_{R}}\left(\frac{\pi_{t}}{\pi}\right)^{\phi_{\pi}\left(1-\phi_{R}\right)}\left(\frac{Y_{t}}{Y_{t-1}}\right)^{\phi_{Y}\left(1-\phi_{R}\right)} \tau_{t}
$$

where $R$ is the steady state policy rate, $\phi_{R}$ captures the degree of interest rate smoothing, $\phi_{\pi}$ is the weight assigned to inflation, $\phi_{Y}$ is the weight assigned to output growth and $\tau_{t}$ is 
a monetary policy shock.

Government spending is assumed to be exogenous and a fixed fraction of steady state output:

$$
G_{t}=Z_{t}^{g} g \bar{Y}
$$

where $Z_{t}^{g}$ is a shock to government spending, $g \in(0,1)$ and $\bar{Y}$ is steady state output. We assume that initial government debt is zero and that the government budget is balanced in each period, i.e. $G_{t}=T_{t}+I C_{t}$, where $I C_{t}$ is the fraction of real output of insolvent firms that covers insolvency proceeding cost, i.e. $I C_{t}=\int_{\underline{\omega}}^{\tilde{\omega} t}(1-\chi) Y_{t} f\left(\omega_{t}\right) d \omega_{t}$.

The market clearing condition in the goods market is: ${ }^{12}$

$$
\begin{aligned}
Y_{t}= & C_{t}+I_{t}+G_{t}+\frac{\kappa}{2}\left(\frac{Z_{t}^{i} I_{t}}{I_{t-1}}-\delta\right)^{2} I_{t}+\frac{\theta}{2}\left(\Pi_{t}-1\right)^{2} Y_{t} \\
& +\frac{\vartheta}{2}\left(\Pi_{t}^{W}-1\right)^{2} w_{t}+\frac{\zeta}{2}\left(\frac{E Q_{t-1}^{R}}{L_{t-1}^{R}}-\nu\right)^{2} \frac{E Q_{t-1}^{R}}{\Pi_{t}} .
\end{aligned}
$$

The model includes eight shocks. The shock processes are given by:

$$
\log \left(s_{t}\right)=\left(1-\rho_{s}\right) \log (\bar{s})+\rho_{s} \log \left(s_{t-1}\right)+\epsilon_{t}^{s},
$$

where $s_{t} \in\left(Z_{t}^{a}, Z_{t}^{c}, Z_{t}^{i}, Z_{t}^{g}, Z_{t}^{e}, \xi_{t}, \phi_{t}, \tau_{t}\right)$ and $\epsilon_{t}^{s}$ is a normally distributed random shock with zero mean and constant variance $\sigma_{s}$.

\section{Estimation}

We estimate the parameters of the model with standard Bayesian methods after loglinearizing the equilibrium conditions around the steady state with zero inflation. The estimation procedure can be summarized as follows. First, the solution of the linearized model is written in state space form. Second, the Kalman filter is used to construct the likelihood function. Third, on basis of Bayes' theorem the posterior kernel function is set

\footnotetext{
${ }^{12}$ Note that the clearing house's net cash flow is: $\Omega_{t}=L_{t}^{R}-L_{t-1}^{R} / \Pi_{t}$.
} 
up by combining the likelihood function with the prior distributions of the model parameters. Fourth, the posterior kernel is maximized with respect to the parameters. ${ }^{13}$ Finally, we resort to the Metropolis Hastings (HM) sampling algorithm with four Markov-Chains to numerically evaluate the posterior distributions of the parameters as well as the other moments of interest. ${ }^{14}$ Before presenting our estimation results, we discuss the data, the calibrated parameters and the priors.

\subsection{Data}

We use data on ten euro area macroeconomic variables over the period 2000Q1-2015Q4. We resort to the following series: (1) log of real output, (2) log of real private consumption, (3) log of real gross fixed capital formation, (4) log of hours worked, (5) quarterly consumer price inflation, (6) quarterly inflation of hourly wages, (7) the log of the real volume of outstanding loans to non-financial cooperations, (8) is the corresponding loan rate, (9) the shadow rate of monetary policy, which reflects the monetary policy instrument and (10) the relative price of investment goods. Variables (1)-(6) are taken from EUROSTAT, where hourly wage inflation is computed as the quarterly growth rate of nominal gross wages and salaries divided by aggregate working hours. Variables (7)-(8) are taken from the ECB and comprise an average over all maturities. ${ }^{15}$ The ECB's policy rate is approximated by variable (9), which is taken from Krippner $(2013,2014)$ and derived from a term structure model. It is designed to capture the true stance of monetary policy, especially in periods characterized by a combination of a (nearly) binding zero lower bound constraint on nominal short-term interest rates on the one hand, and sizable unconventional monetary policy measures on

\footnotetext{
${ }^{13}$ As optimization algorithm we employ the Covariance Matrix Adaptation Evolution Strategy which is included in DYNARE.

${ }^{14}$ The MH method belongs to a broader class of Monte-Carlo-Markov-Chain algorithms used to numerically recover posterior distributions. We parameterize the $\mathrm{MH}$ with a scale factor of 0.35 which ensures an acceptance rate of around 0.25. Moreover, we simulate four Markov-Chains each consisting of 250.000 draws. Following Brooks and Gelman (1998) this turns to be sufficient to ensure convergence of the Markov-Chains according to univariate and multivariate statistics.

${ }^{15}$ The nominal loan volume is deflated by the deflator of consumer prices. Quarterly interest rates are calculated as averages of monthly interest rates.
} 
the other. The extraordinary expansionary stance of monetary policy in such periods is most likely not properly reflected in the standard policy instrument, i.e. the policy rate on the main refinancing operations. Finally, variable (10) is constructed as the ratio of two deflators, i.e. that of gross fixed capital formation and that of private consumption. Both deflators are taken from EUROSTAT. The relative price of investment in the model corresponds to the inverse of the Lagrangean multiplier $\gamma_{t}$ attached to the law of motion of productive capital (see equation (11)).

Since the model is stationary in the relative deviations from the respective steady state levels, all observable variables need to be transformed accordingly. Following Smets and Wouters (2002) the real variables are detrended by a linear trend, while the inflation rates and nominal interest rates are demeaned. Figure 2 plots the transformed data.

\subsection{Calibrated parameters and prior assumptions}

In the literature dealing with the estimation of DSGE models it has become standard to calibrate a subset of the structural model parameters describing the evolution of the economy (Smets and Wouters, 2002). Basically, this is done for the reason of dimensionality and because some parameters can be barely identified based on the typical set of observable macroeconomic aggregates. Following the bulk of research on estimated DSGE models we calibrate five model parameters that are considered difficult to estimate properly. These are the subjective discount factor of households $\beta$, the inverse of the intertemporal elasticity with respect to consumption $\sigma$, the inverse of the Frish elasticity of labor supply $\eta$, the elasticity of capital in the production function $\alpha$ and the capital depreciation rate $\delta$. The values of these parameters are set in accordance with the literature (Bernanke et al., 1999; Smets and Wouters, 2002). Table 1 summarizes the calibrated parameters. 
Figure 2: Transformed euro area data
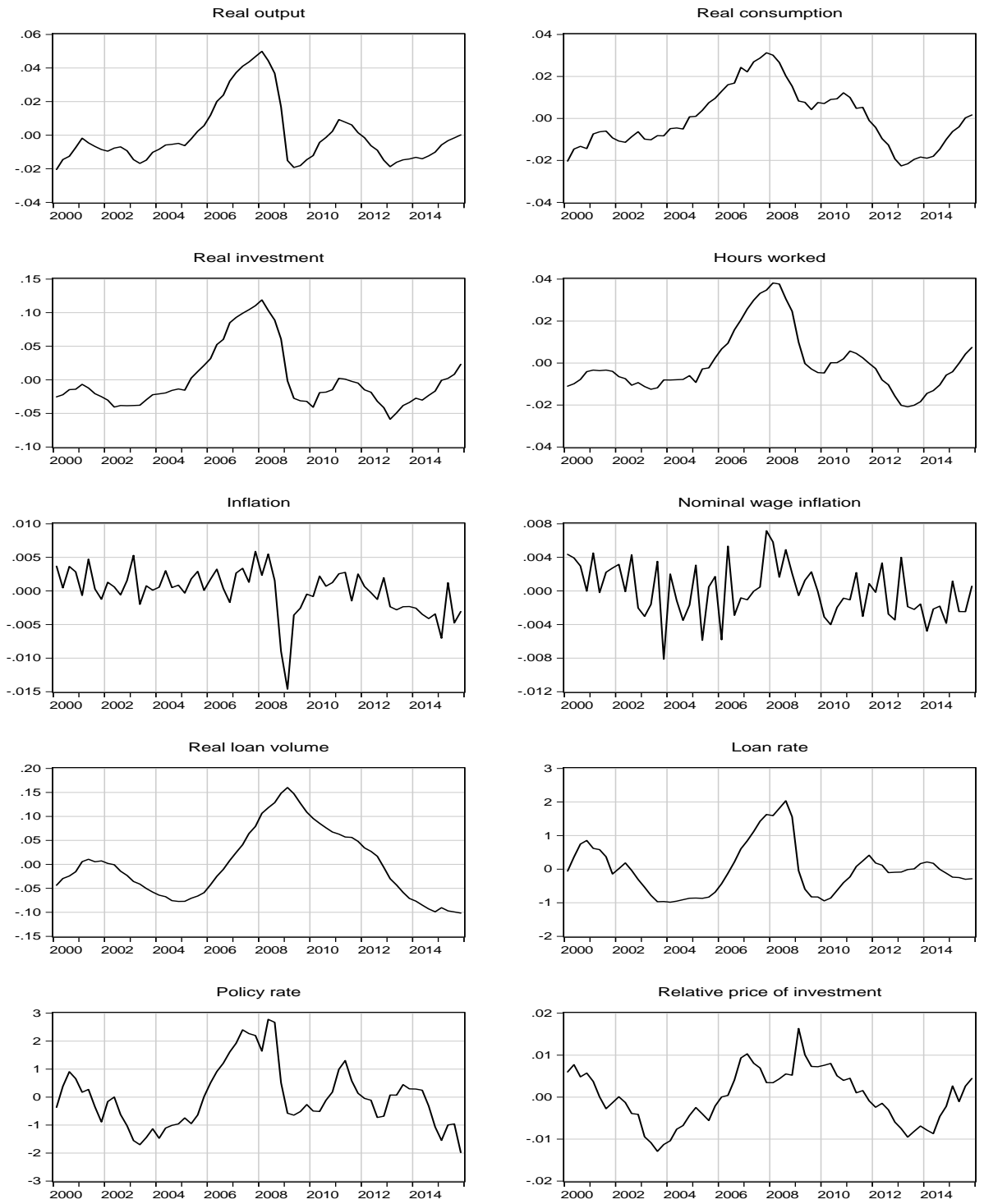

Notes: Log of real variables, i.e. real output, real consumption, real investment, hours worked and the real loan volume are detrended by linear trend. Quarterly inflation rates, interest rates and the relative price of investment are demeaned. 
Table 1: Calibrated parameters

\begin{tabular}{lcl}
\hline \hline Parameter & Description & Value \\
\hline$\alpha$ & Capital elasticity in production function & 0.25 \\
$\delta$ & Capital depreciation rate & 0.025 \\
$\beta$ & Household discount factor & 0.99 \\
$\sigma$ & Risk aversion & 1.0 \\
$\eta$ & Inverse of Frisch elasticity & 1.0 \\
$\xi$ & $\frac{\xi}{\xi-1}$ is the mark-up in the goods market & 7.25 \\
$\phi$ & $\frac{\phi}{\phi-1}$ is the mark-up in the labor market & 5 \\
$\nu$ & Target bank capital to loan ratio & 0.09 \\
$d$ & Steady state firm default rate & 0.03 \\
$E_{\omega}\left[\omega_{t}(j)\right]$ & Mean of idiosyncratic productivity shock & 1 \\
$1-\chi$ & Fraction of output to cover insolvency proceeding cost & 0.2 \\
$g$ & Steady state government spending to GDP ratio & 0.18 \\
\hline \hline
\end{tabular}

Moreover, we assume a mark-up in the goods market of $16 \%$ and set $\xi$ equal to 7.25 . This value corresponds to the estimates provided by Christopoulou and Vermeulen (2012) for the euro area. In the labor market, we follow Smets and Wouters (2002) and set $\phi$ equal to 5, which delivers a mark-up of 20\%. We assume in accordance with Gerali et al. (2010) that the steady state target value of the capital-asset ratio $\nu$ is $9 \%$. This reflects the observation that banks hold a capital buffer to protect themselves against violating the capital adequacy regulation given that the regulation requires that the capital-asset ratio must not fall below $8 \%$. The mean of the expected idiosyncratic productivity shock $E_{\omega}\left[\omega_{t}(j)\right]$ is set to unity. As in Bernanke et al. (1999) we choose an annualized default probability of $3 \%$. The steady state values of the lower and upper bounds of the idiosyncratic productivity shock are then $\underline{\omega}=0.9033$ and $\bar{\omega}=1.097$. Following the discussion in Carlstrom and Fuerst (1997), we assume that the government's insolvency agency keeps $20 \%$ of insolvent firms' output to cover insolvency proceeding costs, i.e. $\chi$ is calibrated to 0.8 . This gives an annualized steady state spread between the lending rate and the policy rate $\rho^{L}$ of $2.56 \%$, which corresponds to the empirical average of the difference between the interest rate set on loans to non-financial 
cooperations and the shadow rate. Finally, we set the steady state government spending to GDP ratio to $18 \%$. Table 1 summarizes the calibrated parameters.

Our choice of priors follows the standards reported in the related DSGE literature. Columns 2-4 in Tables 2 and 3 summarize the assumptions regarding the prior distributions of the estimated model parameters and the variances of the shocks. Accordingly, all adjustment cost parameters are assumed to follow a Gamma distribution, while the parameters in the central bank reaction function related to the inflations rate and output growth are assumed to be normally distributed. The standard errors are set such that the domain covers a reasonable range of possible values. Parameters that should only take values between 0 and 1, like the consumption habit coefficient, the interest rate smoothing coefficient and the autocorrelation coefficients of the shock processes are assumed to follow a Beta distribution covering a range between 0 and 1 . The variances of the shocks are assumed to have an Inverse-Gamma distribution with mean 0.01 and standard deviation of 0.05 . This distribution guarantees a positive variance with a sufficient large domain. To "let the data speak" regarding the most crucial parameters $\theta, \vartheta, \kappa$ and $\zeta$, the corresponding priors are chosen to be substantially wider, i.e. less informative, than usually assumed in the related literature.

\subsection{Posterior estimates}

Columns 5-7 in Tables 2 and 3 report summary statistics of the posterior distribution of the parameters. ${ }^{16}$ The means of the parameters in the central bank reaction function suggest a strong response to inflation fluctuations in the euro area (posterior mean of $\phi_{\pi}$ is 3.83), a no discernible reaction to GDP growth (0.05) and a high degree of interest rate inertia (0.87). The reaction to inflation is more pronounced compared to the estimates of Gerali et al. (2010) or Quint and Rabanal (2014) who use similar interest rate rules. An

\footnotetext{
${ }^{16}$ To avoid the stochastic singularity stemming from the fact that the number of observable variables is larger than the number of structural shocks - i.e. 10 versus 8 , we include a sufficient number of measurement errors (see e.g. Fernndez-Villaverde et al. (2016)).
} 
explanation for the discrepancy are the different assumptions about the timing of events and the different time periods considered, i.e. our sample also includes the period 2012-2015 in which quarterly inflation was almost continuously below its mean. ${ }^{17}$

Concerning nominal rigidities we find that the mean of the parameters reflecting price stickiness $\theta$ and wage stickiness $\vartheta$ are much lower than in other studies (see e.g. Gerali et al. (2010)). The same holds for the degree of habit formation in consumption. The posterior mean of $h$ is 0.26 , which is compared to the results of Smets and Wouters (2002) or Gerali et al. (2010) comparatively low (0.55 and 0.86, respectively). Presumably, this discrepancy reflects our assumption that factor input decisions as well as the wage setting decision are taken one period in advance. These additional restrictions effectively increase the degree of real and nominal rigidities. Accordingly, relatively low values of $\theta, \vartheta$ and $h$ are sufficient for our model to be able to replicate the persistence and volatility in the observable time series used in the estimation. The mean of the investment adjustment cost parameter $\kappa$ is 9.23. Furthermore, the mean of the bank capital adjustment cost parameter $\zeta$ is around 20, and thus notably higher than the estimate in Gerali et al. (2010) who report a mean of 11.07. A possible explanation for this might be the different forces determining the interest rate spread, $R_{t}^{L}-R_{t}$. While in the model of Gerali et al. (2010) the spread largely reflects the different degrees of interest rate stickiness and monopoly power in the credit and deposit market, in our model the spread is affected by the default premium $\rho_{t}^{L}$, which in case of unpredicted loan losses has a feedback impact on the bank capital position and, thus on marginal bank capital adjustment cost. Finally, all shocks are quite persistent with the exception of the monetary policy shock.

The estimates are robust with regard to (a) employing different algorithms for maxi-

\footnotetext{
${ }^{17}$ In Appendix $\mathrm{C}$ we report the parameter estimates of a model specification in which all decisions are taken after the realization of aggregate shocks. In this framework, the mean of the parameter in the central bank's reaction function governing the response to inflation fluctuations amounts to 1.62. Estimating our model over the period 2000-2011 gives a mean of the same parameter of 3.6.
} 
mizing the posterior mode, (b) different starting values for the estimate parameters, (c) changing the number and composition of observational errors. In addition, excluding the relative price of investment from the list of observable variables barely affects the estimates with one exception: the autocorrelation and standard deviation of the investment specific shock, $\rho_{I}$ and $\sigma_{I}$, are no longer identified, i.e. their respective posterior distributions simply resemble the corresponding priors.

Table 2: Priors and posteriors: Structural model parameters

\begin{tabular}{rrrrrrrrr}
\hline \hline & \multicolumn{3}{c}{ Prior distribution } & & \multicolumn{3}{c}{ Posterior distribution } \\
\cline { 2 - 3 } Parameter & Shape & Mean & Std. dev. & & Mean & Lower & Upper $^{1}$ \\
\hline Adjustment costs: & & & & & & \\
$\theta$ & Gamma & 50 & 40 & & 10.79 & 5.12 & 16.35 \\
$\vartheta$ & Gamma & 100 & 60 & & 41.73 & 22.14 & 61.70 \\
$\kappa$ & Gamma & 5 & 5 & & 9.23 & 1.42 & 16.81 \\
$\zeta$ & Gamma & 35 & 20 & & 20.06 & 11.04 & 28.29
\end{tabular}

Habit coefficient:

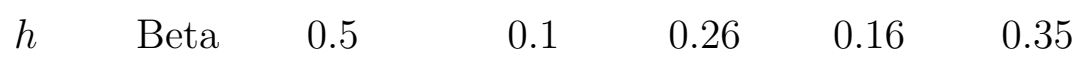

Taylor rule:

\begin{tabular}{rrrrrrr}
$\phi_{\pi}$ & Normal & 2.5 & 1 & 3.83 & 2.58 & 5.09 \\
$\phi_{Y}$ & Normal & 0.1 & 0.25 & 0.05 & -0.29 & 0.38 \\
$\phi_{R}$ & Beta & 0.8 & 0.1 & 0.87 & 0.83 & 0.91 \\
\hline
\end{tabular}

Notes: ${ }^{1}$ Upper and lower - $90 \%$ bounds of posterior distribution. 
Table 3: Priors and posteriors: Exogenous processes

\begin{tabular}{|c|c|c|c|c|c|c|}
\hline \multirow[b]{2}{*}{ Parameter } & \multicolumn{3}{|c|}{ Prior distribution } & \multicolumn{3}{|c|}{ Posterior distribution } \\
\hline & Shape & Mean & Std. dev. & Mean & Lower $^{1}$ & Upper $^{1}$ \\
\hline \multicolumn{7}{|c|}{ AR coefficients: } \\
\hline$\rho_{P}$ & Beta & 0.80 & 0.1 & 0.69 & 0.59 & 0.79 \\
\hline$\rho_{A}$ & Beta & 0.80 & 0.1 & 0.84 & 0.80 & 0.90 \\
\hline$\rho_{\theta}$ & Beta & 0.80 & 0.1 & 0.82 & 0.73 & 0.90 \\
\hline$\rho_{\vartheta}$ & Beta & 0.80 & 0.1 & 0.49 & 0.37 & 0.61 \\
\hline$\rho_{I}$ & Beta & 0.80 & 0.1 & 0.48 & 0.35 & 0.61 \\
\hline$\rho_{G}$ & Beta & 0.80 & 0.1 & 0.68 & 0.58 & 0.78 \\
\hline$\rho_{E Q}$ & Beta & 0.80 & 0.1 & 0.59 & 0.47 & 0.72 \\
\hline$\rho_{M}$ & Beta & 0.80 & 0.1 & 0.24 & 0.15 & 0.32 \\
\hline \multicolumn{7}{|c|}{ Standard deviations: } \\
\hline$\sigma_{P}$ & Inv. Gamma & 0.01 & 0.05 & 0.0104 & 0.0081 & 0.0127 \\
\hline$\sigma_{A}$ & Inv. Gamma & 0.01 & 0.05 & 0.0054 & 0.0046 & 0.0061 \\
\hline$\sigma_{\theta}$ & Inv. Gamma & 0.01 & 0.05 & 0.0030 & 0.0020 & 0.0040 \\
\hline$\sigma_{\vartheta}$ & Inv. Gamma & 0.01 & 0.05 & 0.0025 & 0.0019 & 0.0031 \\
\hline$\sigma_{I}$ & Inv. Gamma & 0.01 & 0.05 & 0.0129 & 0.0108 & 0.0150 \\
\hline$\sigma_{G}$ & Inv. Gamma & 0.01 & 0.05 & 0.0199 & 0.0167 & 0.0229 \\
\hline$\sigma_{E Q}$ & Inv. Gamma & 0.01 & 0.05 & 0.2026 & 0.1198 & 0.2870 \\
\hline$\sigma_{M}$ & Inv. Gamma & 0.01 & 0.05 & 0.0017 & 0.0014 & 0.0020 \\
\hline
\end{tabular}

Notes: ${ }^{1}$ Upper and lower - $90 \%$ bounds of posterior distribution.

Finally, Table 4 shows the unconditional variance decomposition. The figures in columns 2-4 reflect the percentage contributions of the different types of structural shocks to the volatility of a number of endogenous model variables. The shocks are summarized into three categories: demand shocks, supply shocks and a financial shock. ${ }^{18}$ The latter reflects the shock to bank capital.

\footnotetext{
${ }^{18}$ See the notes in Table 4 for the definition of demand and supply shocks.
} 
Table 4: Unconditional variance decomposition

\begin{tabular}{lrrr}
\hline \hline Model variable & $\begin{array}{r}\text { Demand } \\
\text { shocks }\end{array}$ & $\begin{array}{r}\text { Supply } \\
\text { shocks }\end{array}$ & $\begin{array}{r}\text { Financial } \\
\text { shock }\end{array}$ \\
\hline Output & 10.87 & 66.25 & 22.87 \\
Consumption & 16.16 & 65.15 & 18.68 \\
Investment & 0.21 & 94.87 & 4.92 \\
Hours worked & 21.11 & 36.11 & 42.77 \\
Inflation rate & 67.36 & 19.27 & 13.37 \\
Real capital rental rate & 9.81 & 45.19 & 45.00 \\
Real wage & 25.8 & 45.83 & 28.38 \\
Real loan volume & 10.08 & 39.59 & 50.32 \\
Lending rate & 4.16 & 14.12 & 81.73 \\
Default risk & 45.45 & 46.34 & 8.22 \\
Real bank capital & 1.11 & 0.41 & 98.48 \\
\hline \hline
\end{tabular}

Notes: Demand shocks comprise the preference shock, the government spending shock and the monetary policy shock. Supply shocks consist of the aggregate productivity shock, the price mark-up shock, the wage mark-up shock and the shock to the efficiency of investment. Finally, the financial shock reflects the shock to bank capital.

The variance decomposition shows that the importance of the financial shock in addition to demand and supply shocks is quite sizable. We find that the financial shock has not only an impact on the development of the financial variables, but also on the variables related to the real economy.

\section{Impulse response analysis}

Next, we discuss the dynamics of our model. We consider the impulse responses of the model variables to five shocks, namely a preference shock, a monetary policy shock, a government spending shock, a shock to bank capital and an aggregate productivity shock. ${ }^{19}$ We quantify the contribution of important features of our model, i.e. the presence of an endogenous link between aggregate loan losses and bank capital as well as bank capital adjustment cost, by comparing the benchmark model BM impulse responses to those generated

\footnotetext{
${ }^{19}$ The results of the effects of price and wage mark-up shocks and an investment efficiency shock are not reported here, but available on request.
} 
from two alternative model specifications, each of them parameterized with the posterior means reported in Tables 2 and 3: (a) NFF - a model with our timing of events, but with no financial frictions, i.e. where the loan rate equals the policy rate and bank capital is absent; and, (b) ND - a model in which banks are able to insure themselves against losses in their loan portfolios, which is achieved by receiving appropriate lump-sum government transfers. ND shares the same timing assumptions as in BM and incorporates bank capital adjustment costs. The model is comparable to the framework of Bernanke et al. (1999) in which firms are subject to a time varying risk premium due to idiosyncratic risk, but financial intermediaries do not face loan losses due to aggregate shocks.

Additionally, we consider a model in which the timing of events and the structure of the loan contract are the same as in Agénor et al. (2014). In particular, every period decisions regarding current period's working hours, capital input, nominal prices and wages as well as loan contracts are taken after observing the current aggregate state, but before the realization of idiosyncratic shocks. ${ }^{20}$ Consequently, the loan contract is intra-period and contingent on the current aggregate state. Idiosyncratic risk is however still operative. We parameterize the model in two alternative ways: (a) AT - by using the posterior means reported in Tables 2 and 3, and, (b) ATE - by fitting the model to the data, i.e. we set the model parameters in accordance to newly estimated posterior means and standard deviations of the shocks, which are derived by adopting the same estimation method described above. ${ }^{21}$ We start our analysis by comparing the impulse responses of BM to those generated from NFF and ND.

\subsection{The role of unexpected loan losses for the propagation of shocks}

Figures 3-7 summarize the impulse responses to the different shocks. A general result of our analysis is that the inclusion of unexpected losses to banks' loan portfolios amplifies the effects of shocks hitting the real economy. Compared to the model without financial frictions

\footnotetext{
${ }^{20}$ See Appendix B for a summary of this model specification.

${ }^{21}$ See Appendix C for the summary statistics of the posterior distribution of the parameters of this model specification.
} 
NFF we find that unexpected loan losses act like a financial accelerator. This finding holds in particular for the preference shock, the government spending shock and the monetary policy shock.

\subsubsection{Preference shock}

The economy slips into a recession after a negative preference shock (Figure 3). Output falls together with the inflation rate. Consumption drops, investment declines and the situation on the labor market deteriorates. The central bank decreases the policy rate. While all models have these features in common quantitative differences in the reaction of the model variables can be observed.

Firms can at first only react to a fall in aggregate demand by lowering their prices, which explains the massive drop of the inflation rate after the shock. The economy-wide default rate increases due to the scaling up of the real value of outstanding debt. This is easily recognized by inspecting equation (23) that specifies the equilibrium insolvency threshold $\tilde{\omega}_{t}$. In particular, up to a linear approximation, the default rate $\tilde{\omega}_{t}$ is perfectly negatively correlated with current inflation $\Pi_{t}{ }^{22}$ This mechanism is akin to the Fisher debt deflation effect described in Christiano et al. (2010). Expected future default rates are also expected to be above average due to the persistent increase in real wages and the real rental rate of capital, even though the demand for both labor and investment decreases. This again is a manifestation of the Fisher effect: Although the nominal price of both production factors decrease and overall nominal loan demand contracts, their corresponding real values become larger relative to real output with the consequence of a higher insolvency rate. ${ }^{23}$

\footnotetext{
${ }^{22}$ Note that for a given aggregate productivity level, $\tilde{Y}_{t}$ does not respond to shocks in $t$ while the priceadjustment cost term do not have any first order effects on $\tilde{\omega}_{t}$.

${ }^{23}$ The preference shock alters the marginal rate of substitution between consumption and leisure with the consequence of putting upward pressure on real wages. This, combined with the strong drop in consumer price inflation on impact, leads to a significant rise in real wages even though nominal wages decline. This incentivizes firms to substitute labor for capital which, in turn, contributes to the increase in the rental rate of capital. As a result, the real value of loans relative to that of output rises, leading to a higher default premium. An additional consequence of the substitution across production factors, is the relatively muted decline of investment.
} 
Accordingly, the default premium $\rho_{t}^{L}$ increases and stays above average for about two years, which strongly contributes to the rise in the credit spread $R_{t}^{L}-R_{t}$. The elevated default rates reduce banks' profits which translates into a decline of bank capital that reinforces the upward pressure on the loan rate, thus further deteriorating credit conditions.

Comparing BM to ND reveals that the reaction of the economy to the shock is amplified once creditors' default affects bank balance sheets. The effect is strongest for investment where the maximum response more than doubles. The amplification with respect to the reaction of output, consumption and hours worked is also substantial - it amounts to about $30 \%$. The relatively weaker responsiveness of the macro aggregates in ND is the consequence of the following mechanism. Since the increase in firm defaults induced by the preference shock does not translate into higher losses in the aggregate loan portfolio, the capital position of the banking sector develops much more favourably - it improves on impact and remains better than average for more than a year before returning to normal levels. As a result, the additional costs related to deviations from the target level of capitalization are relatively more limited, which in turn allows banks in ND to charge a much lower credit spread even though the fraction of insolvencies is similar to that in the benchmark economy. Consequently, firms cut labor and capital demand by less. 
Figure 3: Contractionary preference shock
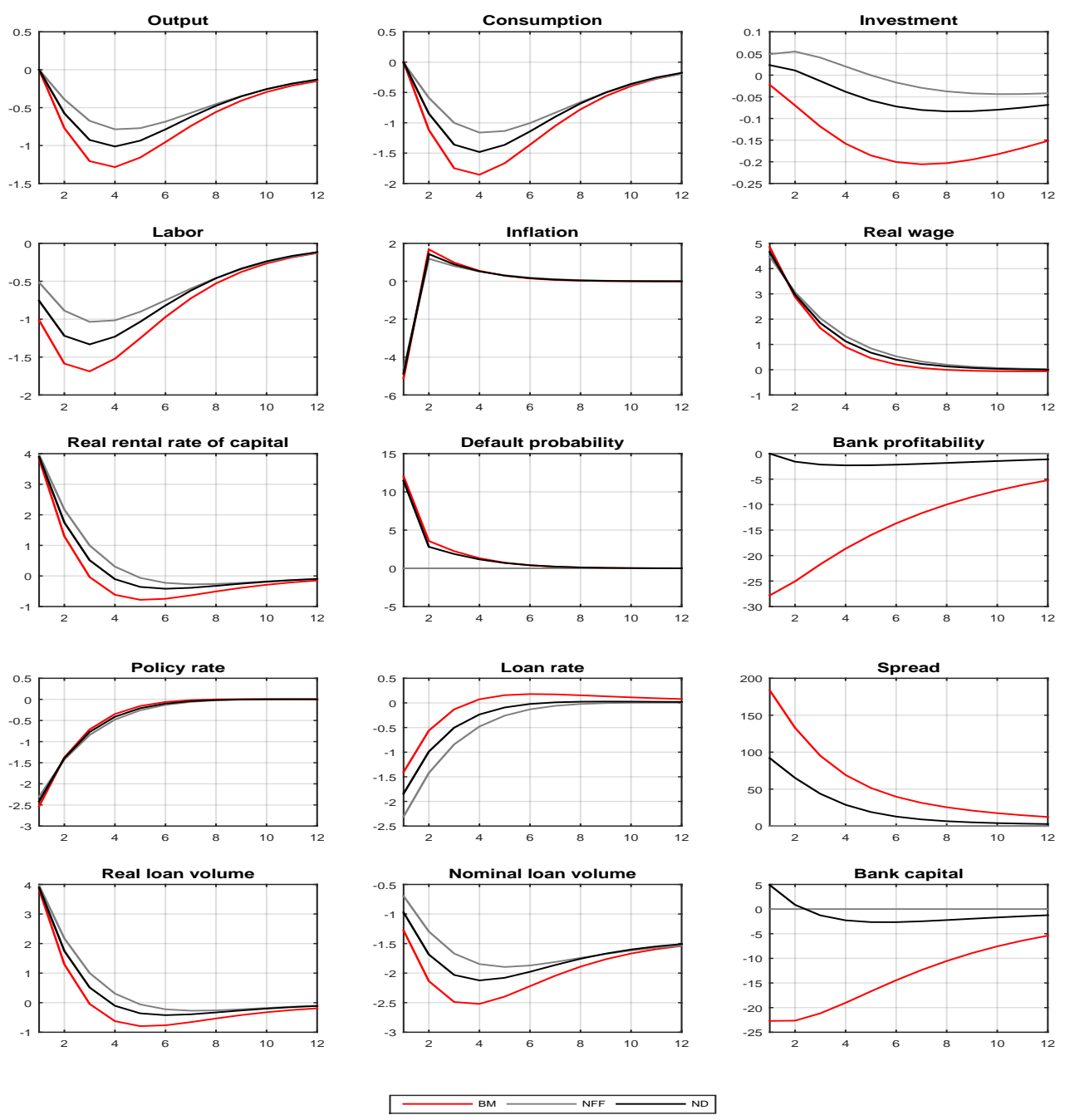

Notes: Impulse responses to a contractionary preference shock. BM - benchmark model; NFF - model without financial frictions and bank capital. Same parameters as in baseline model; ND - baseline model without effects of defaults on bank capitalization. Same parameters as in baseline model. Percentage deviations from steady state except the default probability, loan rate and policy rate for which the deviations are given in percentage points. The shock is normalized such that the maximum response of GDP in the ND model equals $1 \%$. The default probability is given by $\left(\tilde{\omega}_{t}-\underline{\omega}\right) /(\bar{\omega}-\underline{\omega})$.

In addition, the impulse responses to the preference shock reveal that the direction in which the credit spread and the default threshold respond is not driven by the presence of 
non-diversifiable lending risk. As discussed in Section 4.2, the behavior of these variables is rather a consequence of the specific timing according to which several important decisions - e.g. regarding production factors, nominal wages, the premium $\rho_{t}^{L}$ and the loan rate $R_{t}^{L}$ are taken one period in advance, i.e. prior to the realization of next period shocks.

\subsubsection{Monetary policy and government spending shocks}

Output falls together with the inflation rate on impact after both a restrictive monetary policy and government spending shock (Figures 4 and 5). The mechanisms at work are qualitatively the same as in the case of a preference shock. Again, the presence of financial frictions acts as an amplifier of the economy-wide responses to the tightening engineered by the monetary authority or the government, with a notable contribution by the link between non-diversifiable aggregate loan-risk and bank balance sheets.

In fact, a comparison between BM and ND shows that when banks' loan portfolios are subject to aggregate losses, the maximum reaction of output strengthens by about $15 \%$ in the case of a monetary policy shock. In the case of a government spending shock, the maximum output response is even magnified by roughly $40 \%$. Note that the contraction in public spending leads to an increase in private consumption via a standard crowding in mechanism. The increase in consumption, reduces the resources available for investment. This, combined with the decline in overall demand amplifies the negative reaction of investment relative to the case of a monetary policy or a preference shock. Moreover, a notable difference in the reaction of bank capital to the shocks can be observed. Bank capital falls considerably in the case where loan losses affect bank balance sheet, whereas it improves - at least temporarily - if loan losses are compensated. 
Figure 4: Contractionary monetary policy shock
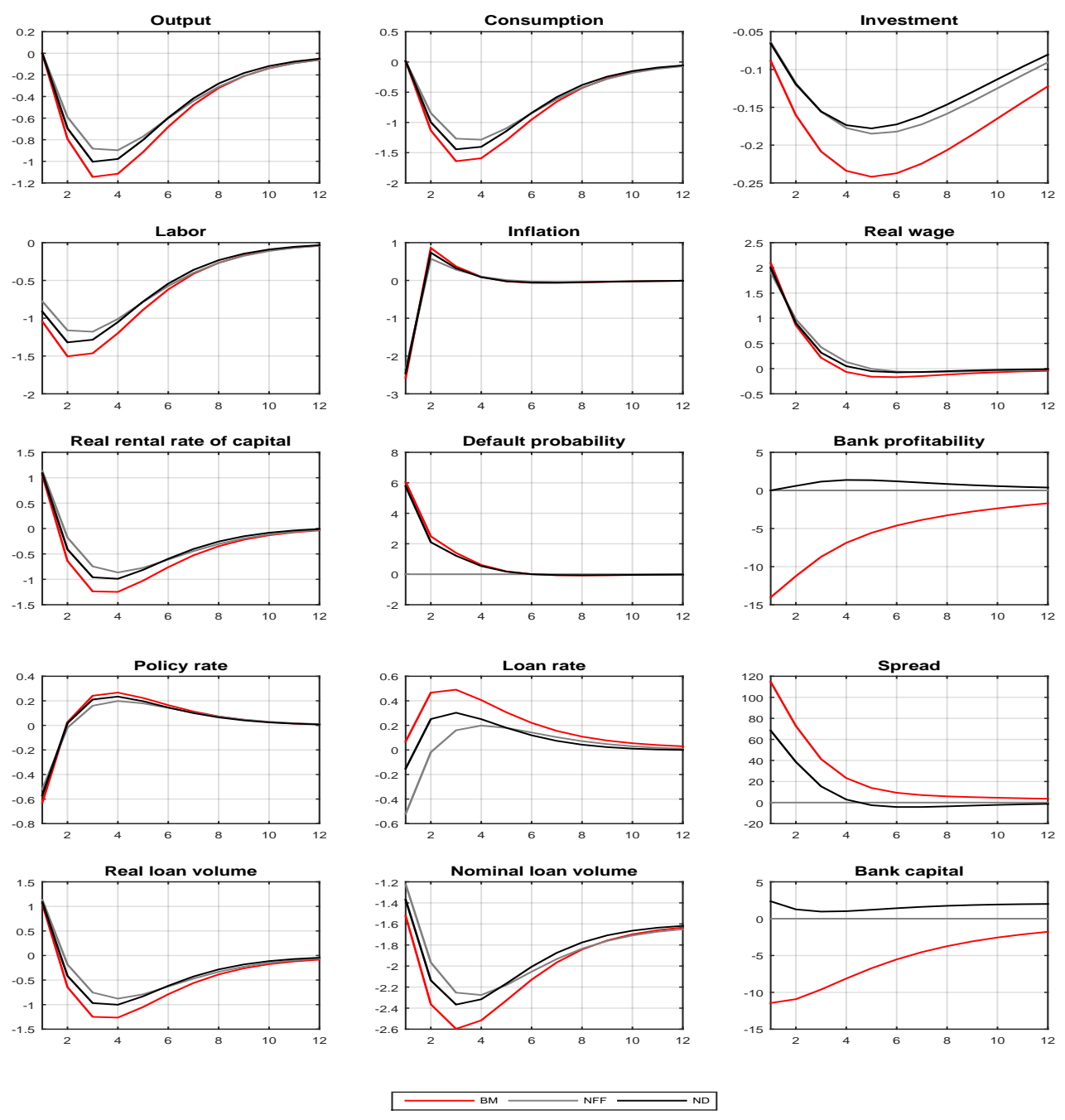

Notes: Impulse responses to a contractionary monetary shock. BM - benchmark model; NFF - model without financial frictions and bank capital. Same parameters as in baseline model; ND - baseline model without effects of defaults on bank capitalization. Same parameters as in baseline model. Percentage deviations from steady state except the default probability, loan rate and policy rate for which the deviations are given in percentage points. The shock is normalized such that the maximum response of GDP in the ND model equals $1 \%$. The default probability is given by $\left(\tilde{\omega}_{t}-\underline{\omega}\right) /(\bar{\omega}-\underline{\omega})$. 
Figure 5: Contractionary government spending shock
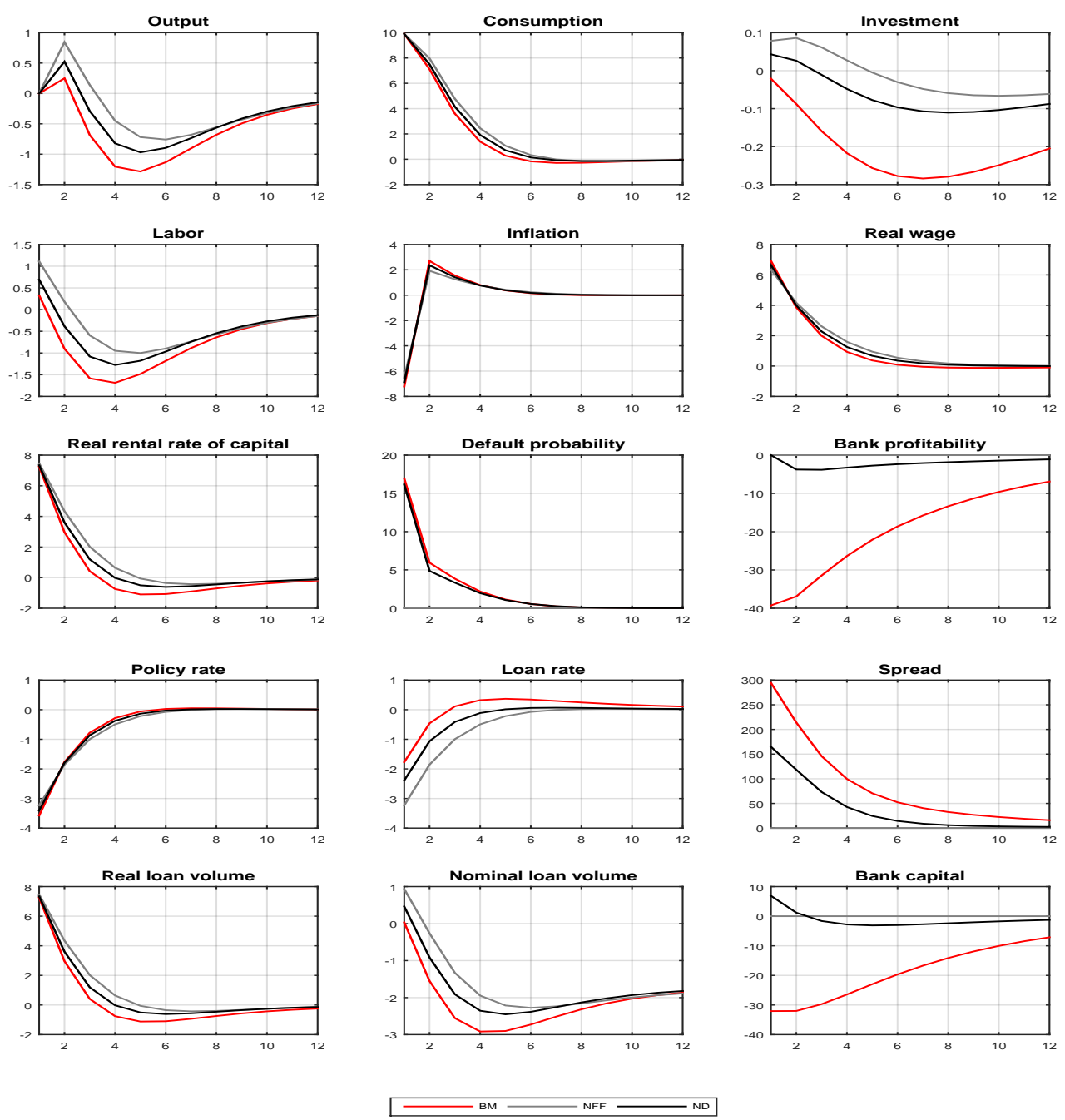

Notes: Impulse responses to a contractionary government spending shock. BM - benchmark model; NFF model without financial frictions and bank capital. Same parameters as in baseline model; ND - baseline model without effects of defaults on bank capitalization. Same parameters as in baseline model. Percentage deviations from steady state except the default probability, loan rate and policy rate for which the deviations are given in percentage points. The shock is normalized such that the maximum response of GDP in the ND model equals $1 \%$. The default probability is given by $\left(\tilde{\omega}_{t}-\underline{\omega}\right) /(\bar{\omega}-\underline{\omega})$.

\subsubsection{Shock to bank capital}

The economy slumps after an adverse shock to bank capital (Figure 6). Bank lending contracts. The loan rate raises in accordance with the weaker bank capital position, thereby 
increasing the threshold of default. The negative consequences of the shock are relatively persistent. Overall, the dynamics of the model variables is comparable to the responses documented in Christiano et al. (2014) to an unanticipated risk shock. Moreover, the reaction of the variables across the different models is very similar. The inability of banks to insure their loan portfolios against aggregate risks contributes modestly, by about $10 \%$, to the amplification of the output response (compare BM with ND in Figure 6).

\subsubsection{Aggregate productivity shock}

The bulk of the DSGE models incorporating financial frictions predict that the latter barely affect the propagation of supply side shocks. Our framework delivers a similar implication (Figure 7). In the following, we only discuss the reaction to an aggregate productivity shock.

In particular, the presence of an operative interrelation between aggregate default rates and bank capitalization contribute qualitatively to the amplification of the responses to productivity shocks. However, this contribution is quantitatively negligible and thus, economically insignificant. The reason is that there are two opposite effects on the default threshold $\tilde{\omega}$ which almost offset each other. On the one hand, the drop in aggregate productivity makes insolvencies more likely. On the other hand, the increase in inflation reduces the real debt burden faced by firms, thus making it easier to repay outstanding debts. As a result, the default threshold and the default premium increase by a relatively limited amount. Accordingly, the banks' capital position deteriorates to a much smaller extent than in the case of the demand-side and financial shocks discussed above. Consequently, the credit spread rises only slightly implying an overly modest difference regarding the behavior of loan rates and thus, regarding factor input demand and pricing across the three models BM, ND and NFF. Nevertheless, two qualitative differences between BM and ND can be observed. First, in BM bank profitability, i.e. the ratio of bank profit over total assets, is pro-cyclical, whereas in ND it is counter-cyclical. Second, the drop of bank capital in BM in response to the shock 
is considerably stronger.

Figure 6: Contractionary bank capital shock
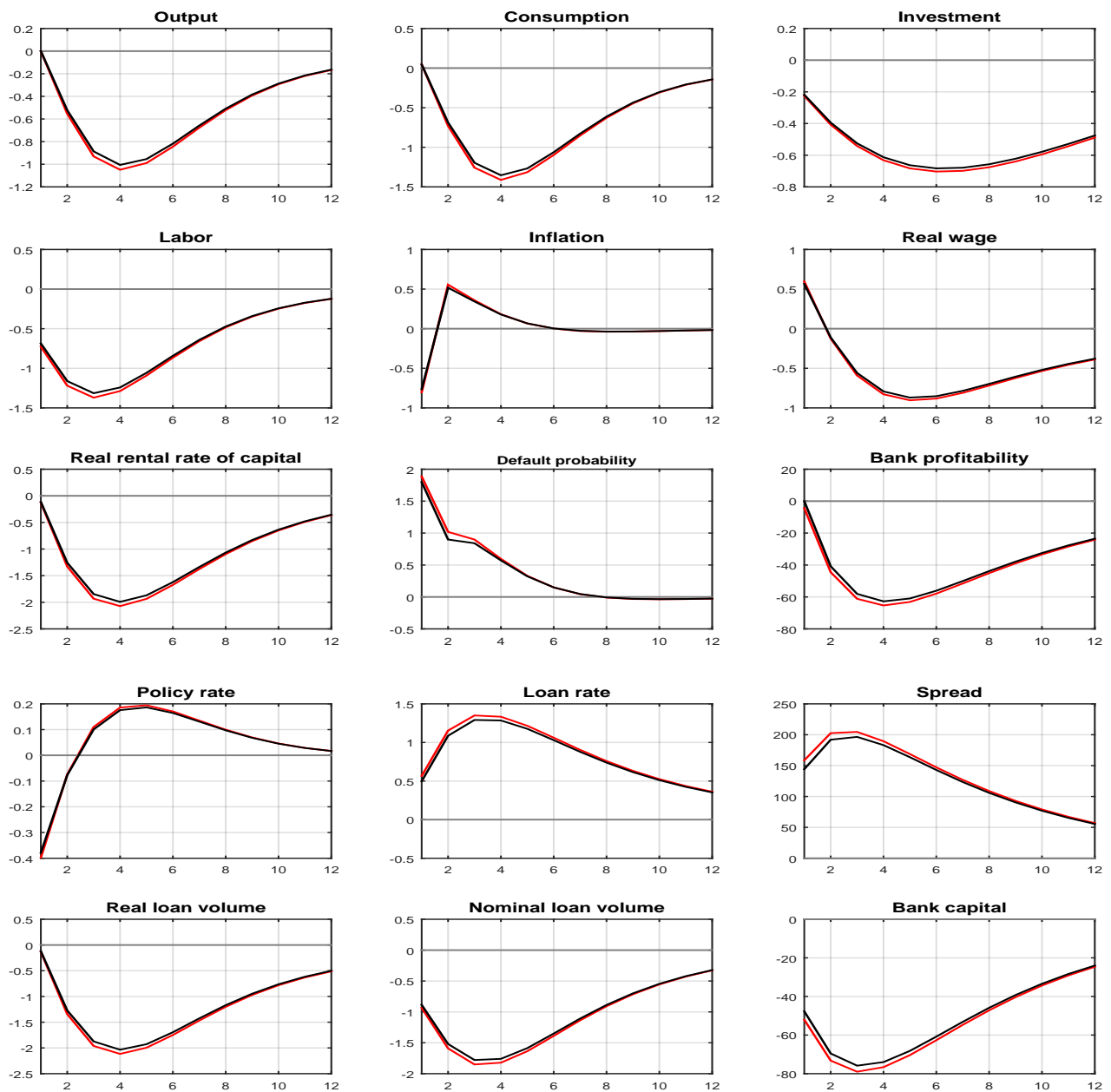

$=\mathrm{BM}=\mathrm{NFF}$

Notes: Impulse responses to an adverse bank capital shock. BM - benchmark model; NFF - model without financial frictions and bank capital. Same parameters as in baseline model; ND - baseline model without effects of defaults on bank capitalization. Same parameters as in baseline model. Percentage deviations from steady state except the default probability, loan rate and policy rate for which the deviations are given in percentage points. The shock is normalized such that the maximum response of GDP in the ND model equals $1 \%$. The default probability is given by $\left(\tilde{\omega}_{t}-\underline{\omega}\right) /(\bar{\omega}-\underline{\omega})$. 
Figure 7: Contractionary aggregate productivity shock
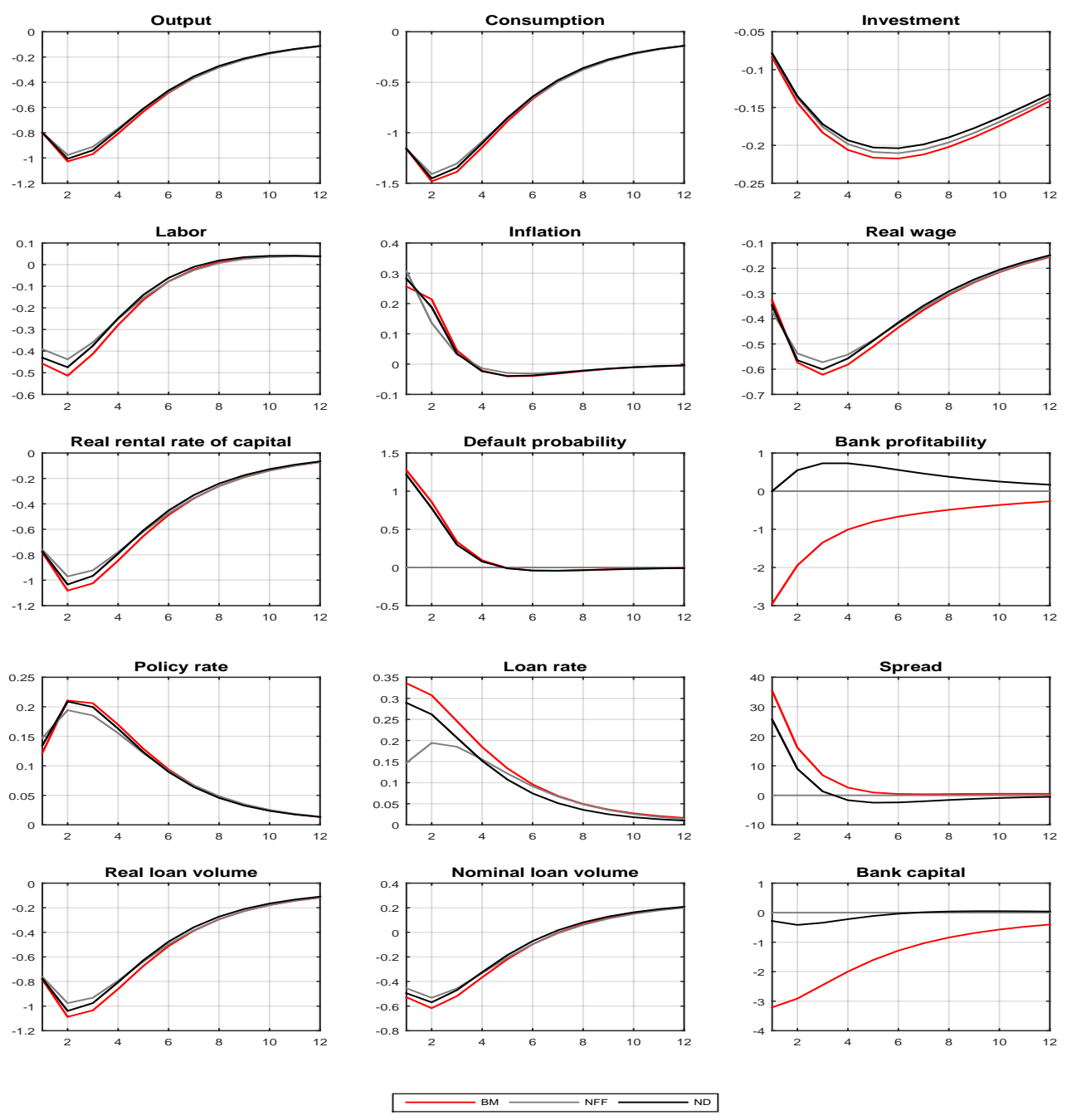

Notes: Impulse responses to an adverse aggregate productivity shock. BM - benchmark model; NFF - model without financial frictions and bank capital. Same parameters as in baseline model; ND - baseline model without effects of defaults on bank capitalization. Same parameters as in baseline model. Percentage deviations from steady state except the default probability, loan rate and policy rate for which the deviations are given in percentage points. The shock is normalized such that the maximum response of GDP in the ND model equals $1 \%$. The default probability is given by $\left(\tilde{\omega}_{t}-\underline{\omega}\right) /(\bar{\omega}-\underline{\omega})$.

\subsection{Alternative timing of events}

Next, we compare BM to a model with a standard timing of events: AT or ATE, respectively, in which decisions regarding capital and labor inputs, wage setting and labor supply are 
taken in the current period, after the realization of aggregate shocks. In AT or ATE, banks and firms sign an intra-period loan contract. Figure 8 summarizes the results.

Figure 8: Role of alternative timing of events
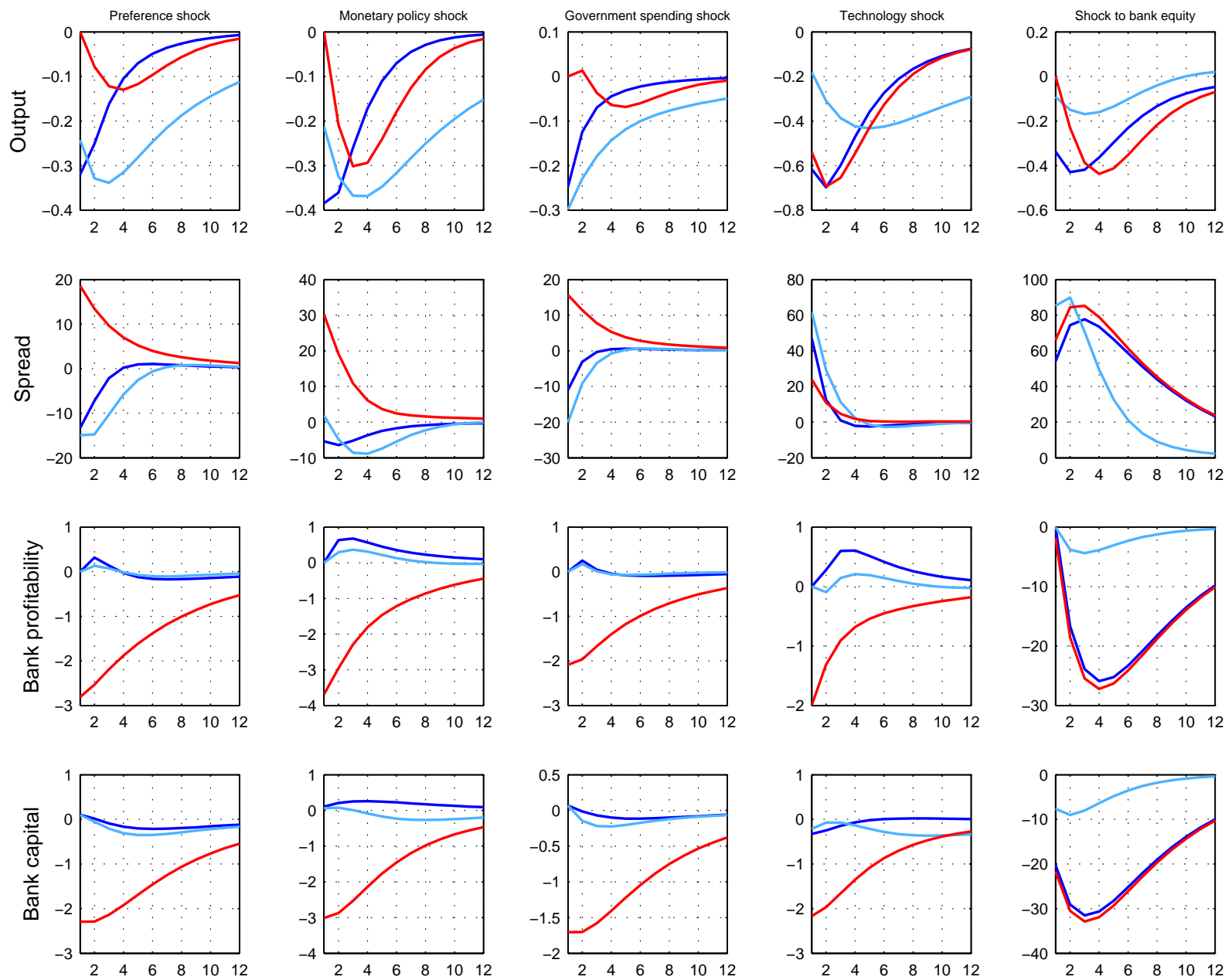

Notes: Impulse responses to different macroeconomic shocks. BM - baseline model; AT - model with alternative timing of events and intra-period loan contracts. Same parameters as in baseline model; ATE - model with alternative timing of events and intra-period loan contracts. Estimated parameters. Percentage deviations from steady state. Each shock is a one-standard deviation shock.

As explained above, the responses to nominal and real demand-side shocks in BM are 
shaped by the Fisher effect. On impact, it increases the real value of the debt burden while, in the following periods, it operates through the induced rise in the real prices of capital and labor which more than offset the decline in loan demand. As a result, the default rate rises with adverse implications for the credit spread, bank profitability and bank capitalization. In contrast, the default threshold in AT or ATE declines after an adverse shock to preferences, monetary policy or government spending, which is caused by the decline in loan demand due to lower cost of working capital and the fall in the loan rate. As a result, the default premium decreases, and thus the interest spread declines. Thus, although the economy slips into a recession after negative demand-side shocks, firms' creditworthiness improves because they need less external financing. Consequently, in AT or ATE bank profitability also increases.

Comparing the responses of BM with those of AT or ATE to an adverse aggregate productivity shock shows that the dynamics are alike except for the response of bank profitability. In case of an adverse shock to bank capital qualitative differences in the reaction of the variables across the different model specifications cannot be observed.

\subsection{Final assessment}

Overall, comparing our model to alternative model specifications, i.e. ND or AT and ATE, respectively shows that the allowance of unexpected losses in banks' loan portfolios generates two important effects. First, BM can replicate the empirical correlation between bank profitability, i.e. the ratio of bank profit to total assets, and aggregate output. Albertazzi and Gambacorta (2009), Bikker and $\mathrm{Hu}$ (2002) and Bolt et al. (2012) find that this correlation is significantly positive in the data. ${ }^{24}$ While our model implies that bank profitability is pro-cyclical, it is counter-cyclical in the alternative models where banks are insulated from aggregate loan losses. The respective correlations evaluated over all shocks amount to 0.75 (BM), -0.14 (ND), -0.11 (AT) and -0.08 (ATE).

\footnotetext{
${ }^{24}$ See also the literature cited in these papers for more empirical evidence.
} 
Second, BM is capable of replicating the dynamic responses of firm default rates and credit spreads to monetary policy shocks. Empirical evidence from De Graeve and Kick (2008), Gilchrist and Zakrajsek (2013), Buch et al. (2014), Gertler and Karadi (2015) or Guidolin et al. (2015) documents that an unexpected monetary tightening leads to higher bankruptcy rates and an increase in the credit spread while the opposite holds for the case of expansionary monetary policy interventions. ${ }^{25}$ In contrast, the models with an alternative timing of events and intra-period loans, i.e. AT and ATE, respectively predict a pro-cyclical response of default rates and credit spreads to monetary policy disturbances.

\section{Conclusion}

We have presented a stylized DSGE model in which banks face unexpected loan losses due to aggregate shocks while, at the same time, being subject to regulatory capital requirements. We have used the framework to explore the importance of an endogenous feedback loop between private debtors' default, aggregate loan losses, bank capital and credit conditions for the transmission of macroeconomic shocks. The model has been estimated using euro area data over the period 2000Q1-2015Q4. We have compared the dynamics of our model to those of alternative model specifications in which loan losses can be insured at no cost or in which all decisions are taken after the realization of aggregate shocks, which means that every loan contract is intra-period and thus contingent on the current aggregate state.

Our main findings are the following. First, the interaction between unexpected losses in banks' loan portfolios and the bank capital position strengthens the effects of real and nominal demand-side shocks. The amplification in the case of disturbances to government spending is particularly strong. The strengthening of the effects arises because of the presence of aggregate loan losses that weaken the bank capital position. The drop of bank

\footnotetext{
${ }^{25}$ In addition, Duffie et al. (2007), Pesaran et al. (2006), Tang and Yan (2010) and Aliaga-Daz and Olivero (2010), among others show that default rates and credit spreads are in general counter-cyclical without identifying specific structural shocks.
} 
capital in turn reinforces the tightening of credit conditions. In contrast, alternative specifications of our model in which aggregate lending risk can be completely hedged exhibit a response of bank capital to these shocks that is at least temporarily positive. Second, our model is capable of reproducing two financial market characteristics that are documented in the empirical literature, i.e. the pro-cyclicality of bank profitability and the counter-cyclical reaction of firm default rates and credit spreads after monetary policy shocks. Alternative specifications of our model in which loan contracts are contingent upon the aggregate state of the economy fail to replicate at least one of these characteristics or even both.

Finally, our model is a stylized attempt to incorporate aggregate loan losses in a DSGE framework, which can be extended along a number of dimensions. In particular, our model abstracts from firms accumulating net worth, assumes a competitive banking sector, neglects global banking and ignores international trade. We believe that extending the framework by these dimensions has the potential for providing interesting insights into the transmission of macroeconomic shocks.

\section{Appendix}

\section{A. Data and sources}

The bank lending data is taken from the ECB and comprises loans extended to the Non-Financial corporations sector, denominated in Euro, stocks, total maturity (data key: BSI.Q.U2.N.A.A20.A.1.U2.2240.Z01.E) and the interest rate on loans other than revolving loans and overdrafts, convenience and extended credit card debt, Non-Financial corporations sector, new business coverage, total amount (data key: MIR.M.U2.B.A2A.A. R.A.2240.EUR.N). The series taken from EUROSTAT correspond to the European System of Accounts 2010 (ESA 2010) and are seasonally adjusted. They include real gross domestic product, real consumption of households and non-profit institutions serving households, real gross fixed capital formation, hours worked, consumer price inflation, nominal gross wages and salaries, deflator of gross fixed capital formation and deflator of private consumption. 
The shadow policy rate is provided by Leo Krippner and available at the homepage of the Reserve Bank of New Zealand. ${ }^{26}$

B. Model without unexpected loan losses

The model without unexpected loan losses can be summarized by the following equations:

$$
\begin{aligned}
& Y_{t}=Z_{t}^{a} K_{t-1}^{\alpha} N_{t}^{1-\alpha} \\
& L_{t}^{R}=z_{t} K_{t-1}+w_{t} N_{t} \\
& z_{t} R_{t}^{L}=\alpha Z_{t}^{a} \mathrm{mc}_{t}\left(\frac{N_{t}}{K_{t-1}}\right)^{1-\alpha} \\
& w_{t} R_{t}^{L}=(1-\alpha) Z_{t}^{a} \mathrm{mc}_{t}\left(\frac{N_{t}}{K_{t-1}}\right)^{-\alpha} \\
& \theta \Pi_{t}\left(\Pi_{t}-1\right)=\theta \beta E_{t}\left[\frac{\lambda_{t+1}}{\lambda_{t}} \Pi_{t+1}\left(\Pi_{t+1}-1\right) \frac{Y_{t+1}}{Y_{t}}\right]+\xi_{t} \mathrm{mc}_{t} \\
& \tilde{\omega}_{t}=\frac{R_{t}^{L} L_{t}^{R}}{\tilde{Y}_{t}}+\frac{\theta}{2}\left(\Pi_{t}-1\right)^{2} \\
& K_{t}=(1-\delta) K_{t-1}+I_{t} \\
& \gamma_{t}=\beta E_{t}\left[\frac{\lambda_{t+1}}{\lambda_{t}}\left(\gamma_{t+1}(1-\delta)+z_{t+1}\right)\right] \\
& \gamma_{t}=1+\kappa\left(\frac{Z_{t}^{i} I_{t}}{I_{t-1}}-\delta\right) \frac{Z_{t}^{i} I_{t}}{I_{t-1}}+\frac{\kappa}{2}\left(\frac{Z_{t}^{i} I_{t}}{I_{t-1}}-\delta\right)^{2} \\
& -\beta E_{t}\left[\frac{\lambda_{t+1}}{\lambda_{t}} \kappa\left(\frac{Z_{t+1}^{i} I_{t+1}}{I_{t}}-1\right) Z_{t+1}^{i}\left(\frac{I_{t+1}}{I_{t}}\right)^{2}\right] \\
& Z_{t}^{c}\left(C_{t}-H_{t}\right)^{-\sigma}=\lambda_{t} \\
& \lambda_{t}=\beta E_{t}\left[\lambda_{t+1} \frac{R_{t}^{D}}{\Pi_{t+1}}\right]
\end{aligned}
$$

\footnotetext{
${ }^{26}$ See Krippner (2013) as well as http://www.rbnz.govt.nz/research-and-publications/researchprogramme/additional-research/measures-of-the-stance-of-united-states-monetary-policy
} 


$$
\begin{aligned}
& \vartheta\left(\Pi_{t}^{W}-1\right) \Pi_{t}^{W}=\vartheta \beta E_{t}\left[\frac{\lambda_{t+1}}{\lambda_{t}}\left(\Pi_{t+1}^{W}-1\right) \frac{\left(\Pi_{t+1}^{W}\right)^{2}}{\Pi_{t+1}}\right] \\
& +\left(1-\phi_{t}\right) N_{t}+\frac{\phi_{t} \xi_{N} N_{t}^{1+\eta}}{\lambda_{t} w_{t}} \\
& w_{t}=\frac{w_{t-1} \Pi_{t}^{W}}{\Pi_{t}} \\
& R_{t}^{L}=R_{t}-\zeta\left(\frac{E Q_{t}^{R}}{L_{t}^{R}}-\nu\right)\left(\frac{E Q_{t}^{R}}{L_{t}^{R}}\right)^{2}+\rho_{t}^{L} \\
& \rho_{t}^{L}=\left(\frac{Y_{t}}{L_{t}^{R}}\right) \frac{(2-\chi) \tilde{\omega}_{t}^{2}-\underline{\omega}\left(2 \tilde{\omega}_{t}-\chi \underline{\omega}\right)}{2(\bar{\omega}-\underline{\omega})} \\
& \bar{R}_{t}^{L}=R_{t}^{L}-\rho_{t}^{L} \\
& (1+v) E Q_{t+1}^{R} \Pi_{t+1}=L_{t}^{R}\left(\bar{R}_{t}^{L}-R_{t}\right)+R_{t} E Q_{t}^{R} \\
& -\frac{\zeta}{2}\left(\frac{E Q_{t}^{R}}{L_{t}^{R}}-\nu\right)^{2} E Q_{t}^{R}+Z_{t+1}^{e} \\
& R_{t}=R^{1-\phi_{R}} R_{t-1}^{\phi_{R}}\left(\frac{\pi_{t}}{\pi}\right)^{\phi_{\pi}\left(1-\phi_{R}\right)}\left(\frac{Y_{t}}{Y_{t-1}}\right)^{\phi_{Y}\left(1-\phi_{R}\right)} \tau_{t}, \\
& G_{t}=Z_{t}^{g} g \bar{Y} \\
& Y_{t}=C_{t}+I_{t}+G_{t}+\frac{\kappa}{2}\left(\frac{Z_{t}^{i} I_{t}}{I_{t-1}}-\delta\right)^{2} I_{t}+\frac{\theta}{2}\left(\Pi_{t}-1\right)^{2} Y_{t} \\
& +\frac{\vartheta}{2}\left(\Pi_{t}^{W}-1\right)^{2} w_{t}+\frac{\zeta}{2}\left(\frac{E Q_{t}^{R}}{L_{t}^{R}}-\nu\right)^{2} E Q_{t}^{R}
\end{aligned}
$$

Real marginal production cost are denoted by $\mathrm{mc}_{t}$. 
C. Posterior estimates of model without unexpected loan losses

Table 5: Priors and posteriors: Structural parameters. Standard timing

\begin{tabular}{rrrrrrrrr}
\hline \hline & \multicolumn{3}{c}{ Prior distribution } & & \multicolumn{3}{c}{ Posterior distribution } \\
\cline { 2 - 3 } Parameter & Shape & Mean & Std. dev. & & Mean & Lower & Upper $^{1}$ \\
\hline Adjustment costs: & & & & & & \\
$\theta$ & Gamma & 50 & 40 & & 27.97 & 9.27 & 53.30 \\
$\vartheta$ & Gamma & 100 & 60 & & 144.70 & 73.99 & 209.61 \\
$\kappa$ & Gamma & 5 & 5 & & 1.28 & 0.52 & 2.12 \\
$\zeta$ & Gamma & 30 & 20 & & 61.19 & 39.68 & 82.05
\end{tabular}

Habit coefficient:

$\begin{array}{lllllll}h & \text { Beta } & 0.5 & 0.1 & 0.83 & 0.76 & 0.91\end{array}$

Taylor rule:

\begin{tabular}{rrrrrrr}
$\phi_{\pi}$ & Normal & 2.5 & 1 & 1.62 & 1.00 & 2.55 \\
$\phi_{Y}$ & Normal & 0.1 & 0.25 & 0.21 & -0.15 & 0.59 \\
$\phi_{R}$ & Beta & 0.8 & 0.1 & 0.77 & 0.67 & 0.90 \\
\hline
\end{tabular}

Notes: ${ }^{1}$ Upper and lower - $90 \%$ bounds of posterior distribution. 
Table 6: Priors and posteriors: Exogenous processes. Standard timing

\begin{tabular}{|c|c|c|c|c|c|c|}
\hline \multirow[b]{2}{*}{ Parameter } & \multicolumn{3}{|c|}{ Prior distribution } & \multicolumn{3}{|c|}{ Posterior distribution } \\
\hline & Shape & Mean & Std. dev. & Mean & Lower $^{1}$ & Upper $^{1}$ \\
\hline \multicolumn{7}{|c|}{ AR coefficients: } \\
\hline$\rho_{P}$ & Beta & 0.80 & 0.1 & 0.62 & 0.48 & 0.75 \\
\hline$\rho_{A}$ & Beta & 0.80 & 0.1 & 0.91 & 0.87 & 0.96 \\
\hline$\rho_{\theta}$ & Beta & 0.80 & 0.1 & 0.76 & 0.65 & 0.88 \\
\hline$\rho_{\vartheta}$ & Beta & 0.80 & 0.1 & 0.44 & 0.32 & 0.57 \\
\hline$\rho_{I}$ & Beta & 0.80 & 0.1 & 0.65 & 0.48 & 0.81 \\
\hline$\rho_{G}$ & Beta & 0.80 & 0.1 & 0.87 & 0.80 & 0.94 \\
\hline$\rho_{E Q}$ & Beta & 0.80 & 0.1 & 0.66 & 0.52 & 0.80 \\
\hline$\rho_{M}$ & Beta & 0.80 & 0.1 & 0.36 & 0.25 & 0.46 \\
\hline \multicolumn{7}{|c|}{ Standard deviations: } \\
\hline$\sigma_{P}$ & Inv. Gamma & 0.01 & 0.05 & 0.0042 & 0.0036 & 0.0047 \\
\hline$\sigma_{A}$ & Inv. Gamma & 0.01 & 0.05 & 0.0042 & 0.0036 & 0.0047 \\
\hline$\sigma_{\theta}$ & Inv. Gamma & 0.01 & 0.05 & 0.0032 & 0.0022 & 0.0043 \\
\hline$\sigma_{\vartheta}$ & Inv. Gamma & 0.01 & 0.05 & 0.0023 & 0.0017 & 0.0028 \\
\hline$\sigma_{I}$ & Inv. Gamma & 0.01 & 0.05 & 0.0135 & 0.0098 & 0.0173 \\
\hline$\sigma_{G}$ & Inv. Gamma & 0.01 & 0.05 & 0.0188 & 0.0160 & 0.0214 \\
\hline$\sigma_{E Q}$ & Inv. Gamma & 0.01 & 0.05 & 0.0750 & 0.0497 & 0.1036 \\
\hline$\sigma_{M}$ & Inv. Gamma & 0.01 & 0.05 & 0.0015 & 0.0013 & 0.0018 \\
\hline
\end{tabular}

Notes: ${ }^{1}$ Upper and lower - $90 \%$ bounds of posterior distribution.

\section{References}

Agénor, P.-R., Bratsiotis, G. J., Pfajfar, D., July 2014. Credit frictions, collateral, and the cyclical behavior of the finance premium. Macroeconomic Dynamics 18 (05), 985-997.

Albertazzi, U., Gambacorta, L., 2009. Bank profitability and the business cycle. Journal of Financial Stability 5 (4), 393-409.

Aliaga-Daz, R., Olivero, M. P., August 2010. Is there a financial accelerator in US banking?: Evidence from the cyclicality of banks' price-cost margins. Economics Letters 108 (2), 167-171.

Angeloni, I., Faia, E., 2013. Capital regulation and monetary policy with fragile banks. Journal of Monetary Economics 60 (3), 311-324.

Barth, M. J. I., Ramey, V. A., February 2002. The cost channel of monetary transmission. In: NBER Macroeconomics Annual 2001, Volume 16. NBER Chapters. National Bureau of Economic Research, Inc, pp. 199-256.

Benassy, J.-P., 1995. Money and wage contracts in an optimizing model of the business cycle. Journal of Monetary Economics 35 (2), 303-315.

Benes, J., Kumhof, M., 2015. Risky bank lending and countercyclical capital buffers. Journal of Economic Dynamics and Control 58 (C), 58-80.

Bernanke, B., Lown, C. S., 1991. The credit crunch. Brookings Papers on Economic Activity 22 (2), 205-248.

Bernanke, B. S., Gertler, M., Gilchrist, S., 1999. The financial accelerator in a quantitative business cycle framework. In: Taylor, J. B., Woodford, M. (Eds.), Handbook of Macroeconomics: Vol. I. Elsevier Science B.V., pp. 1341-1392.

Berrospide, J. M., Edge, R. M., 2010. The effects of bank capital on lending: What do we know, and what does it mean? Finance and Economics Discussion Series 44, Federal Reserve Board. 
Bikker, J. A., Hu, H., 2002. Cyclical patterns in profits, provisioning and lending of banks and procyclicality of the new Basel capital requirements. BNL Quarterly Review 55 (221), 143-175.

Bolt, W., de Haan, L., Hoeberichts, M., van Oordt, M. R., Swank, J., 2012. Bank profitability during recessions. Journal of Banking \& Finance 36 (9), 2552-2564.

Borio, C., Zhu, H., 2012. Capital regulation, risk-taking and monetary policy: A missing link in the transmission mechanism? Journal of Financial Stability 8 (4), 236-251.

Brooks, S. P., Gelman, A., 1998. General methods for monitoring convergence of iterative solutions. Journal of Computational and Graphical Statistics 7 (4), 434-455.

Buch, C. M., Eickmeier, S., Prieto, E., 2014. In search for yield? Survey-based evidence on bank risk taking. Journal of Economic Dynamics and Control 43, 12 - 30.

Carlstrom, C. T., Fuerst, T. S., December 1997. Agency costs, net worth, and business fluctuations: A computable general equilibrium analysis. American Economic Review 87 (5), 893-910.

Cecchetti, S. G., Li, L., October 2008. Do capital adequacy requirements matter for monetary policy? Economic Inquiry 46 (4), 643-659.

Cho, J.-O., Cooley, T. F., June 1995. The business cycle with nominal contracts. Economic Theory 6 (1), $13-33$.

Christiano, L., Eichenbaum, M., 1992. Liquidity effects and the monetary transmission mechanism. American Economic Review, Papers and Proceedings 92, 346-353.

Christiano, L., Motto, R., Rostagno, M., 2008. Shocks, structures or monetary policies? The Euro Area and US after 2001. Journal of Economic Dynamics and Control 32 (8), 2476-2506.

Christiano, L., Motto, R., Rostagno, M., 2010. Financial factors in economic fluctuations. Working Paper Series 1192, European Central Bank.

Christiano, L. J., Eichenbaum, M., Evans, C., 1997. Sticky price and limited participation models of money: A comparison. European Economic Review 41, 1201-1249.

Christiano, L. J., Eichenbaum, M., Evans, C., 2005. Nominal rigidities and the dynamic effects of a shock to monetary policy. Journal of Political Economy 113, 1-45.

Christiano, L. J., Motto, R., Rostagno, M., 2014. Risk shocks. American Economic Review 104 (1), $27-65$.

Christopoulou, R., Vermeulen, P., 2012. Markups in the Euro area and the US over the period 19812004. A comparison of 50 sectors. Empirical Economics 42 (1), 53-77.

Clerc, L., Derviz, A., Mendicino, C., Moyen, S., Nikolov, K., Stracca, L., Suarez, J., Vardoulakis, A. P., June 2015. Capital regulation in a macroeconomic model with three layers of default. International Journal of Central Banking 11 (3), 9-63.

Davis, S., 2010. The adverse feedback loop and the effects of risk in both the real and financial sectors. Globalization and Monetary Policy Institute Working Paper 66, Federal Reserve Bank of Dallas.

De Graeve, F., Kick, T., 2008. Monetary policy and bank distress: an integrated micro-macro approach. Discussion Paper Series 2: Banking and Financial Studies 2008,03, Deutsche Bundesbank.

De Graeve, F., Kick, T., Koetter, M., 2008. Monetary policy and bank distress: an integrated micro-macro approach. Discussion Paper Series 2 2008,03, Deutsche Bundesbank.

Diamond, D. W., Rajan, R. G., 2001. Liquidity risk, liquidity creation, and financial fragility: A theory of banking. Journal of Political Economy 109 (2), 287-327.

Dib, A., 2010. Capital requirement and financial frictions in banking: Macroeconomic implications. Staff Working Papers 10-26, Bank of Canada.

Duffie, D., Saita, L., Wang, K., 2007. Multi-period corporate default prediction with stochastic covariates. Journal of Financial Economics 83 (3), 635-665.

Fernndez-Villaverde, J., Ramrez, J. F. R., Schorfheide, F., 2016. Solution and estimation methods for DSGE models. NBER Working Papers 21862, National Bureau of Economic Research, Inc.

Fiore, F. D., Tristani, O., 2013. Optimal monetary policy in a model of the credit channel. Economic Journal 123 (571), 906-931.

Freixas, X., Rochet, J.-C., 1997. Microeconomics of banking. MIT Press Cambridge, Massachusetts, Massachusetts.

Gambacorta, L., Shin, H. S., 2016. Why bank capital matters for monetary policy. BIS Working Papers 558, 
Bank for International Settlements.

Garriga, C., Kydland, F. E., Sustek, R., 2016. Nominal rigidities in debt and product markets. Working Paper 22613, National Bureau of Economic Research.

Gerali, A., Neri, S., Sessa, L., Signoretti, F. M., 2010. Credit and banking in a DSGE model of the euro area. Journal of Money, Credit and Banking 42 (s1), 107-141.

Gertler, M., Karadi, P., January 2011. A model of unconventional monetary policy. Journal of Monetary Economics 58 (1), 17-34.

Gertler, M., Karadi, P., 2015. Monetary policy surprises, credit costs, and economic activity. American Economic Journal: Macroeconomics 7 (1), 44-76.

Gilchrist, S., Zakrajsek, E., 2013. The impact of the federal reserve's large - scale asset purchase programs on corporate credit risk. Journal of Money, Credit and Banking 45 (s2), 29-57.

Gray, J. A., 1978. On indexation and contract length. Journal of Political Economy 86 (1), 1-18.

Guidolin, M., Orlov, A. G., Pedio, M., 2015. The impact of monetary policy on corporate bonds under regime shifts. Working Papers 562, IGIER Bocconi University.

Hancock, D., Wilcox, J. A., 1993. Has there been a capital crunch in banking? The effects on bank lending of real estate market conditions and bank capital shortfalls. Journal of Housing Economics 3 (1), 31-50.

Hülsewig, O., Mayer, E., Wollmershäuser, T., October 2006. Bank loan supply and monetary policy transmission in Germany: An assessment based on matching impulse responses. Journal of Banking \& Finance 30 (10), 2893-2910.

Kollmann, R., 2013. Global banks, financial shocks, and international business cycles: Evidence from an estimated model. Journal of Money, Credit and Banking 45 (s2), 159-195.

Kollmann, R., Enders, Z., Müller, G. J., 2011. Global banking and international business cycles. European Economic Review 55 (3), 407-426.

Kopecky, K. J., Van Hoose, D., 2004. Bank capital requirements and the monetary transmission mechanism. Journal of Macroeconomics 26 (3), 443-464.

Krippner, L., 2013. Measuring the stance of monetary policy in zero lower bound environments. Economics Letters 118 (1), 135-138.

Krippner, L., 2014. Measuring the stance of monetary policy in conventional and unconventional environments. CAMA Working Papers 2014-06, Centre for Applied Macroeconomic Analysis, Crawford School of Public Policy, The Australian National University.

Marcucci, J., Quagliariello, M., September 2009. Asymmetric effects of the business cycle on bank credit risk. Journal of Banking \& Finance 33 (9), 1624-1635.

Meh, C. A., Moran, K., March 2010. The role of bank capital in the propagation of shocks. Journal of Economic Dynamics and Control 34 (3), 555-576.

Pesaran, M. H., Schuermann, T., Treutler, B.-J., Weiner, S. M., 2006. Macroeconomic dynamics and credit risk: A global perspective. Journal of Money, Credit and Banking 38 (5), 1211-1261.

Pesaran, M. H., Xu, T., 2011. Business cycle effects of credit and technology shocks in a DSGE Model with firm defaults. CESifo Working Paper Series 3609, CESifo Group Munich.

Pool, S., de Haan, L., Jacobs, J. P., 2015. Loan loss provisioning, bank credit and the real economy. Journal of Macroeconomics 45 (C), 124-136.

Quint, D., Rabanal, P., June 2014. Monetary and macroprudential policy in an estimated DSGE model of the Euro Area. International Journal of Central Banking 10 (2), 169-236.

Rotemberg, J., 1984. A monetary equlibrium model with transaction costs. Journal of Political Economy 92 (Februar), 40-58.

Smets, F., Wouters, R., 2002. An estimated stochastic dynamic general equilibrium model of the euro area. Journal of the European Economic Association 1 (5), 1123-1175.

Tang, D. Y., Yan, H., 2010. Market conditions, default risk and credit spreads. Journal of Banking \& Finance 34 (4), 743-753.

Tornell, A., Westermann, F., 2002. Boom-bust cycles in middle income countries: Facts and explanation. IMF Staff Papers 49 (Special i), 111-155.

Van den Heuvel, S. J., 2002. Does bank capital matter for monetary transmission? Economic Policy Review 
8 (May), 259-265.

Van Hoose, D., 2007. Theories of bank behavior under capital regulation. Journal of Banking \& Finance 31 (12), 3680-3697.

Zhang, L., 2009. Bank capital regulation, the lending channel and business cycles. Discussion Paper Series 1: Economic Studies 2009,33, Deutsche Bundesbank, Research Centre. 